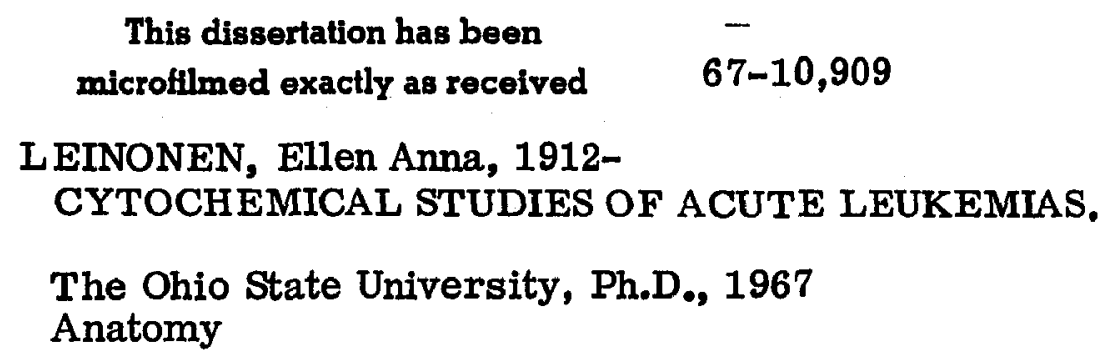


(C) Copyright by

Ellen Anna Leinonen

1967 


\title{
CYTOCHEMICAL STUDIES OF \\ ACUTE LEUKEMIAS
}

\author{
DISSERTATION
}

Presented in Partial Fulfillment of the Requirements for the Degree Doctor of Philosophy in the Graduate School of The Ohio State University

By

Ellen Anna Leinonen, B.S., M.S.

$* * * * * *$

The Ohio State University

1967

Approved by

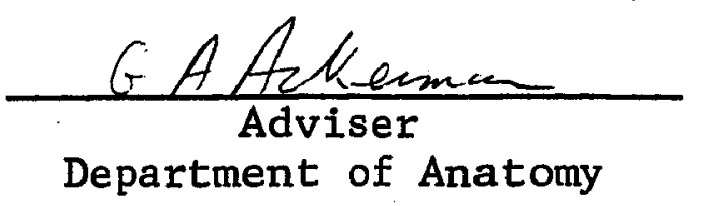


PLEASE NOTE:

Figure pages are not original copy. They tend to "curl". Filmed in the best possible way. University Microfilms, Inc. 


\section{ACKNOWLEDGMENTS}

I wish to thank Dr. Chris J. D. Zarafonetis, Professor of Internal Medicine and Director of Simpson Memorial Institute, The University of Michigan, for his helpful suggestions and for making it possible for me to use laboratory space, equipment, and materials at Simpson Memorial Institute. Also, I am thankful for the diagnoses of the acute leukemias made at Simpson Memorial Institute. The slides on which the diagnoses were made are on file for future study.

I am grateful to Dr. G. Adolph Ackerman, Professor of Anatomy, The Ohio State University, for his helpful comments, suggestions, and assistance throughout the study. I am greatly indebted to him for his excellent advice on the cytochemical aspects of the study.

I am especially grateful to Miss Agnes I. Fritzell, Research Associate at Simpson Memorial Institute, for obtaining specimens for me of blood and bone marrows of patients with acute leukemias. 
I am grateful to Dr. Inta J. Ertel of the Hematological Section of the Department of Pediatrics, University of Michigan, for her interest and cooperation in providing me with blood and bone marrow films of children with acute leukemias.

I wish to thank Dr. James K. Avery and the Research Committee of the School of Dentistry, University of Michigan, for permitting me to use a new research microscope without which the study could not have been completed.

I am grateful to George E. Hess and Louis P. Martonyi for technical assistance with photomicrographs, Mrs. Lilita Austrins for the excellent illustration of charts, and Miss Kathleen Wolf for her interest and skill in typing this manuscript. 
VITA

October 15, 1912 Born - Houghton, Michigan

1949. - . . R.D.H., University of Michigan, Ann Arbor, Michigan

1949-1962.. . . Instructor of Dentistry, Department of Dental Hygiene, University of Michigan, Ann Arbor, Michigan

1956. . . . B.S., University of Michigan, Ann Arbor, Michigan

1962. - . . M.S., University of Michigan, Ann Arbor, Michigan

1964-1967 . . Assistant Professor of Dentistry, Department of Dental Hygiene, University of Michigan, Ann Arbor, Michigan

FIELDS OF STUDY

Major Field: Anatomy

Histology. Professors G. Adolph Ackerman and John A. Eglitis

Embryology. Professors Orville E. Russell and John C. Weston

Neuroanatomy. Professors Lawrence J. Ha11 and Albert 0. Humbertson, Jr.

Physiology. Professor Emil Bozler

Pathology. Professor Dante G. Scarpelli 
TABLE OF CONTENTS

Page

ACKNOWLEDGMENTS . . . . . . . . . . . . . . ii

LIST OF TABLES . . . . . . . . . . . . . . vi

LIST OF CHARTS . . . . . . . . . . . . . vii

LIST OF ILLUSTRATIONS . . . . . . . . . . . . ix

INTRODUCTION . . . . . . . . . . . . . 1

MATERIALS AND METHODS . . . . . . . . . 2

Periodic Acid-Schiff Reaction 4

Sudan Black B Reaction 4

Acid Phosphatase Reaction 5

Alkaline Phosphatase Reaction 5

Nonspecific Esterase Reaction . 5

Phosphorylase Reaction 5

Lactic Dehydrogenase Reaction 6

Semiquantitative Scoring Method 6

OBSERVATIONS . . . . . . . . . . . . . . . 7

DISCUSSION . . . . . . . . . . . 17

SUMMARY . . . . . . . . . . . . . 26

APPENDIX ............... . . . 72

BIBLIOGRAPHY . . . . . . . . . . . . 88 


\section{LIST OF TABLES}

Table

Page

1. Cytological Characteristics in Wright's Stain of the Cells of Blood and Bone Marrow of Patients with Acute Leukemias . . . . . . . . .

2. Mean Scores of Cytochemical Reactions of Patients with Acute Leukemias and Compatible Normal Controls . . . . 30

3. Mean Scores of Alkaline Phosphatase Activity of Mature Neutrophils of Patients with Acute Leukemias and Normal Controls ........... 


\section{LIST OF CHARTS}

Chart

Page

1. PAS Scores of the Primitive Cells of Patients with Acute Leukemias .... 33

2. PAS Scores of the Cells of Blood and Bone Marrow of Normal Controls . . . 35

3. Acid Phosphatase Scores of the Primitive Cells of Patients with Acute Leukemias. . 37

4. Acid Phosphatase Scores of the Cells of Blood and Bone Marrow of Normal. Controls. . . . . . . . . . 39

5. Alkaline Phosphatase Scores of the Mature Neutrophils of Patients-with Acute Leukemias and of Normal Controls. . . . . . . . . . 41

6. Nonspecific Esterase Scores of the Primitive Cells of Patients with Acute Leukemias . . . . . . . . 43

7. Nonspecific Esterase Scores of the Cells of Blood and Bone Marrow of Normal Controls............ 45

8: Phosphorylase Scores of the Primitive Cel1s of Patients with Acute Leukemias. . 
9. Phosphorylase Scores of the Cells of Blood and Bone Marrow of Normal

Controls . . . . . . . . . . 49

10. Lactic Dehydrogenase Scores of the

Primitive Cells of Patients with

Acute Leukemias . . . . . . . . 51

11. Lactic Dehydrogenase Scores of the Ce11s

of Blood and Bone Marrow of Normal

Controls . . . . . . . . . . 53 


\section{LIST OF ILLUSTRATIONS}

Figure

Page

1. Wright's Stain of Lymphoblasts of Acute Lymphocytic Leukemia . . . . . . 55

2. Wright's Stain of Myeloblasts of Acute Granulocytic Leukemia ....... 55

3. Wright's Stain of Monoblasts from Acute Myelomonocytic Leukemia . . . . . 55

4. Wright's Stain of Monoblasts from Acute Monocytic Leukemia . . . . . . 55

5. Periodic Acid-Schiff Activity in Lymphoblasts from Acute Lymphocytic Leukemia . . . . . . . . . . .

6. Periodic Acid-Schiff Activity in Lymphoblasts from Acute Lymphocytic Leukemia . . . . . . . . . . .

7. Periodic Acid-Schiff Reaction in Monoblasts from Acute Monocytic Leukemia . . . . . . . . . . .

8. Periodic Acid-Schiff Activity in a Myeloblast from Acute Granulocytic Leukemia . . . . . . . . . .

9. Periodic Acid-Schiff Activity in a Normal Lymphocyte 
Figure

Page

10. Sudan Black Reaction in Lymphoblasts from Acute Lymphocytic Leukemia . . .

11. Sudan Black Reaction in Monoblasts

from Acute Monocytic Leukemia . . . . 59

12. Sudan Black Reaction in a Normal Myelocyte .......... 59

13. Acid Phosphatase Activity in

Lymphoblasts from Acute Lymphocytic

Leukemia . . . . . . . . . . .

14. Acid Phosphatase Activity in

Lymphoblasts from Acute Lymphocytic

Leukemia . . . . . . . . . . .

15. Acid Phosphatase Activity in Monoblasts

from Acute Monocytic Leukemia . . . .

16. Acid Phosphatase Activity in a

Myeloblast from Acute Granulocytic

Leukemia . . . . . . . . . . .

17. Acid Phosphatase Activity in a Normal

Lymphocyte . . . . . . . . .

18. Acid Phosphatase Activity in a Norma1

Monocyte ........... 63

19. Acid Phosphatase in a Normal Myeloblast.'

20. Nonspecific Esterase Activity in a

Lymphoblast from Acute Lymphocytic

Leukemia 
Figure

Page

21. Nonspecific Esterase Activity in

Monoblasts from Acute Monocytic

Leukemia . . . . . . . . . .

22. Nonspecific Esterase Activity in

Monoblasts from Acute Monocytic

Leukemia . . . . . . . . . . .

23. Nonspecific Esterase Activity in a

Myeloblast from Acute Granulocytic

Leukemia . . . . . . . . . .

24. Nonspecific Esterase Activity in a Norma1 Monocyte . . . . . . . .

25. Nonspecific Esterase Activity in a Normal Myeloblast . . . . . .

26. Phosphorylase Reaction in Lymphoblasts

from Acute Lymphocytic Leukemia. . . .

27. Phosphorylase Activity in Monoblasts from Acute Monocytic Leukemia. . . .

28. Phosphorylase Activity in Granulocytes from Acute Granulocytic Leukemia . . . 67

29. Phosphorylase Activity in a Normal

Lymphocyte . . . . . . . . 69

30. Phosphorylase Activity in a Normal

Monocyte . . . . . . . . . . 
31. Lactic Dehydrogenase Activity in Lymphoblasts from Acute Lymphocytic Leukemia

32. Lactic Dehydrogenase Activity in Monoblasts from Acute Monocytic Leukemia

33. Lactic Dehydrogenase Activity in a Myeloblast from Acute Granulocytic Leukemia

34. Lactic Dehydrogenase Activity in a Normal Lymphocyte

35. Lactic Dehydrogenase Activity in a Normal Monocyte

36. Lactic Dehydrogenase Activity in a Norma1 Myeloblast. 
The morphological identification of the blood and bone marrow cells of normal individuals and patients with leukemia using Romanowsky stains is well recognized. This staining method has been widely used for the differential diagnoses of hematological disorders. However, in leukemia using only morphological criteria, distinction between the types of stem cells has been difficult。

Recent studies have applied cytochemical methods extensively in studying acute leukemias. Most investigators, however, have employed only one or two cytochemical reactions $.18,37,38,90,101,103,106,179$

Variations in glycogen $2,3,37,38,90,124$ and 1ipids $87,101,106,145,179$ and the differences in the reactivity of alkaline phosphatase, 7,87,90,102,176, 200 acid phosphatase, 70, 103, 122 nonspecific esterase, 18, 87, 203 sulfhydryls, 26, 27,43 aminopeptidase, 6,9 phosphorylase, 77,87 and lactic dehydrogenase 87,162 have been described in the blood and bone marrow cells 
of normal individuals and patients with acute leukemias. Such observations suggest that cytochemical studies do provide additional criteria for the differentiation and classification of the acute leukemias. The cytological and cytochemical methods used in the present study have been directed toward the morphological, chemical, and enzymatic differentiation and the subsequent classification of the primitive cells of the acute leukemias. In combining cytochemical and morphological analysis, it should be possible to correlate alterations in cellular structure with differences in chemical composition. Recent evidence has indicated that the major defect in the acute leukemias is the impairment of cellular differentiation and maturation.62,64,65,177 Therefore, studies directed toward obtaining cytochemical profiles of the primitive cells may be of valuable assistance in determining the cause or causes underlying the alterations in cellular development.

$$
\text { MATERIALS AND METHODS }
$$

Blood and bone marrow films were obtained from 71 patients with acute leukemia; 29 with acute 1ymphocytic 
Ieukemia (ALL); 23 with acute monocytic leukemia (AML); 19 with acute granulocytic leukemia (AGL) including 5 patients in the acute phase of chronic granulocytic leukemia. When the blood and bone marrow films were procured, 17 of the patients with ALL had been treated (5 with 6-mercaptopurine, 4 with prednisone, 4 with cytosine, 3 with amethopterin, 1 with amethopterin and hydrocortisone) and 12 had had no therapy; 12 of the patients with AML had been treated (9 with 6-mercaptopurine, 2 with hydrocortisone, 1 with prednisone and 6-mercaptopurine) and 11 were untreated; 12 of the patients with AGL had been treated ( 6 with myleran, 3 with hydrocortisone and 6-mercaptopurine, 2 with 6-mercaptopurine, 1 with hydrocortisone) and 7 were untreated. The diagnoses of the type of acute leukemias were made at Simpson Memorial Institute and the Hematological Section of the Department of Pediatrics, University of Michigan.

Controls consisted of blood films from 12 healthy laboratory workers, bone marrows from 4 healthy adults, and 3 patients with non-hematological diseases. 
Included in the controls were 6 patients with idiopathic thrombocytopenic purpura (4 were untreated and 2 were in remission). A11 patients used as controls had normal lèukocyte counts and differentials. Morphological evaluation of the blood and bone marrow films of the patients with acute leukemia and the controls was accomplished by examining films stained with Wright's stain. Cytochemical characteristics were amassed by using seven cytochemical reactions: periodic acidSchiff reaction, Sudan black B reaction, and reactions for acid phosphatase, a1kaline phosphatase, nonspecific esterase, phosphorylase, and lactic dehydrogenase.

Periodic Acid-Schiff Reaction. The periodic acidSchiff reaction with salivary amylase digestion was used for the identification of glycogen and glycoprotein. Formalin vapor was used as the fixative.

Sudan Black B Reaction. The method of Sheehan and Storey (1947) was employed for the demonstration of lipids. Air dried films were fixed in formalin vapor and immersed in the Sudan black B staining solution for one hour at room temperature. 
Acid Phosphatase Reaction. Acid phosphatase activity was demonstrated by the naphthol AS-BI phosphate hexazonium pararosanilin method described by Goldberg and Barka (1962). Formo1 vapor, formol-calcium fixation was employed and the films were incubated in the substrate solution for one and one-half hours at thirty-seven degrees Centigrade.

Alkaline Phosphatase Reaction. The naphthol AS-MX phosphate-Fast blue RR method of Ackerman (1962) was employed for the localization of alkaline phosphatase activity. The formol-methanol fixed films were incubated for forty-five minutes at room temperature.

Nonspecific Esterase Reaction. Naphthol AS acetateFast blue BB method of Wachstein and Wolf (1958) was used to demonstrate nonspecific esterase activity. The films were fixed in formalin vapor and incubated for ninety minutes at room temperature.

Phosphorylase Reaction. The phosphorylase method of Takeuch 1 and Kinoshita (1956) as modified by Eräk" and Palkama (1961) was employed in this study. However, a higher concentration of glucose-1-phosphate (150 mg/m1) 
and glycogen $(10 \mathrm{mg} / \mathrm{ml})$ was used in the substrate solution. These changes appeared to improve the sensitivity of the phosphorylase reaction.

Lactic Dehydrogenase Reaction. The Quaglino and Hayhoe (1960) procedure was employed for the localization of lactic dehydrogenase activity. Acetone-fixed films were incubated in the substrate solution with nitro BT as the tetrazolium salt for one to two hours at thirty-seven degrees Centigrade.

Semiquantitative Scoring Method. A semiquantitative scoring method ${ }^{16}$ was used for estimating the intensity of the cytochemical enzyme reactions of the primitive cells of patients with acute leukemias and blood and bone marrow cells of normal controls. The rating of individual cells was as follows:

0 Colorless

1+ Diffuse staining or fine granules, or both; 5 to 15 granules.

2+ Moderate; moderately coarse granules; 16 to 30 granules.

3+ Strong; coarse granules; 31 to 45 granules. 
4+ Intense; densely packed or very coarse granules and/or clumps of reactive material; 45 or more granules.

Using this scoring procedure, the highest mean score possible would be four hundred. To obtain a total score, one hundred primitive cells of patients with acute leukemias were counted for each reaction. Lymphocytes, monocytes, and myeloblasts of normal individuals were used as appropriate controls, and one hundred cells of each type were counted in order to obtain total scores for each reaction. Alkaline phosphatase activity was scored by counting one hundred of the mature neutrophils of the blood and bone marrows of patients with acute leukemias and normal controls.

\section{OBSERVATIONS}

The morphological characteristics of the cells in acute leukemias as observed in Wright's stain are detailed in Table 1. In general, the characteristics conform to criteria used at the University of Michigan and to other observations $46,87,209$ employed in the identification of the various cell types and forms of acute leukemias. 
Periodic Acid-Schiff Reaction. An assessment of the scores of the periodic acid-Schiff reaction (PAS) in ALL varies between 62 and 214 with a mean of 134 (Table 2; Chart 1). Although individual cells exhibit considerable variation in PAS reactivity, the majority of 1ymphoblasts observed in patients with ALL possess a moderate $(+)$ to strong $(++)$ reactivity. In contrast, normal lymphocytes, used as a comparison since 1ymphoblasts are not present in normal blood and bone marrow, exhibit a considerably lower mean score of 39 with a range between 26 and 62 (Table 2; Chart 2)。Cytologica11y, the PAS reactive material in lymphoblasts of ALL has a peripheral cytoplasmic distribution appearing as fine to coarse particulate granules with coarse clumps of positive material frequently seen in some of the cells (Plate II). In lymphocytes of normal blood, the pattern of the PAS reaction is similar (Plate III) to lymphoblasts of ALL, although coarse clumps of positive material are not observed.

The PAS scores of the monoblasts observed in patients with AML vary between 48 and 121 with a mean 
of 88 (Table 2; Chart 1). Many monoblasts show only a diffuse cytoplasmic coloration; other cells have fine granules $(+,++)$, and some cells possess many coarse granules (Plate II) with moderate to strong coloration $(+,++)$. The monocytes in normal blood, used as a standard for comparison of the monoblasts in AML, have similar PAS scores, ranging between 47 and 105 with a mean of 74 (Table 2; Chart 2), and a similar distribution of PAS reactive material.

The PAS scores of the myeloblasts observed in patients with AGL range between 28 and 102 with a mean of 53 (Table 2; Chart 1) and are slightly higher than in the myeloblasts observed in the bone marrow of normal individuals, which range between 21 and 67 with a mean of 35 (Table 2; Chart 2). Many of the myeloblasts of AGL are nonreactive or exhibit a diffuse staining of their cytoplasm (Plate II). Occasionally, particulate glycogen granules can be seen. Myeloblasts from normal individuals exhibit PAS reaction patterns similar to the myeloblasts of AGL, although particulate glycogen granules are not observed. 
Sudan Black B Reaction. Sudan black B reaction shows similar reactions in the primitive cells of the acute leukemias and normal blood and bone marrow cells. Lymphoblasts of ALL and the 1ymphocytes of normal blood are often negative or possess only a few sudanophilic granules (Plate III); monoblasts of AML and monocytes of normal blood demonstrate many small sudanophilic granules scattered throughout the cells (Plate III); myeloblasts of AGL show slightly greater sudanophilic reactions than the myeloblasts of normal blood which have faint reaction patterns. In normal granulocytes, Sudan black B staining appears to increase with the maturation of the cells. Semiquantitative scoring was not done on the Sudan black B reactions.

Acid Phosphatase Reaction. The acid phosphatase scores of the 1ymphoblasts of ALL range between 60 and 131 with a mean of 90 (Table 2; Chart 3) being similar to the acid phosphatase scores of lymphocytes of normal blood which vary between 58 and 120 with a mean of 94 (Table 2; Chart 4). In general, the acid phosphatase activity appears as weak to moderate $(+,+)$. 
Reactivity in the lymphoblasts of ALL localizes in one or more areas near the periphery of the cytoplasm with the most intense reaction appearing near the nuclear hof (Plate IV). In 1ymphocytes of normal blood the pattern is similar to the lymphoblasts with small areas of reactivity localizing near the periphery of the cells (Plate V); an occasional lymphocyte exhibits a more intense perinuclear activity.

The level of acid phosphatase scores of monoblasts of AML appears somewhat higher than that of the 1ymphoblasts of ALL. In monoblasts of AML, the acid phosphatase scores vary between 93 and 155 with a mean of 128 , being similar to the acid phosphatase scores of monocytes of normal blood which have a range between 108 and 150 with a mean of 132 (Table 2; Charts 3,4). The monoblasts of AML exhibit varied reactivity from moderate to strong $(++,++)$. The acid phosphatase activity, localizing primarily in sma11 and large granules, is most intense at the nuclear hof but with some areas of activity appearing near the periphery of the cell (Plate IV). Monocytes of normal blood, like monoblasts of AML, 
exhibit varied degrees of reactivity from moderate to strong $(+,+++)$ with the localization most intense in the perinuclear cytoplasm. An occasional monocyte of normal blood shows intense cytoplasmic activity (P1ate V).

The acid phosphatase scores of the myeloblasts of AGL show a variation between 96 and 143 with a mean of 120. The acid phosphatase scores of the myeloblasts of AGL were judged higher than the acid phosphatase scores of myeloblasts of normal bone marrow which range between 68 and 99 with a mean of 86 (Table 2; Charts 3,4). The myeloblasts of AGL exhibit moderate to strong activity $(++,+++)$ with more granules depositing in a perinuclear position (Plate IV)。 Myeloblasts of normal bone marrow show smaller areas of reactivity with one to several small clusters of granules localizing near the nuclear hof (Plate V).

Alkaline Phosphatase Reaction. The primitive cells in leukemia, like the normal precursor cells, are negative for alkaline phosphatase activity. However, since the alkaline phosphatase activity is demonstrable in the 
mature neutrophils of the patients with acute leukemia, the neutrophils can be used in assessing levels of alkaline phosphatase activity. The results show that the scores of the neutrophils in ALL are the highest with a range between 100 and 272 and a mean of 180. The scores of the neutrophils in AML are intermediate with a range between 35 and 157 and a mean of 91. In AGL the neutrophils show scores, judged the lowest, varying between 9 and 44 with a mean of 25 (Table 3; Chart 5). Many of the neutrophils of AGL appear to have alterations in the size and number of the specific granules. The scores of the neutrophils of normal blood are also intermediate ranging between 60 and 156 with a mean of 82 (Table 3; Chart 5).

Nonspecific Esterase Reaction. The scores of the nonspecific esterase activity of the lymphoblasts of ALL range between 38 and 101 with a mean of 71 being similar to the lymphocytes of normal blood which vary between 42 and 95 with a mean of 68 (Table 2; Charts 6,7). The 1ymphoblasts of ALL have a weak to moderate reactivity $(+,++)$ with fine to coarse granules localizing 
primarily in the perinuclear cytoplasm (Plate V). Lymphocytes of normal blood show similar reactivity $(+,+)$ with a peripheral cytoplasmic distribution of fine to coarse granules.

The monoblasts of AML and the monocytes of normal blood have higher nonspecific esterase scores than the 1ymphoblasts of ALL and the 1ymphocytes of normal blood. The nonspecific esterase scores of the monoblasts of AML range between 120 and 185 with a mean of 144, being similar to the scores of the monocytes of normal blood which vary between 105 and 149 with a mean of 140 (Table 2; Charts 6,7 ). The monoblasts of AML and the monocytes of normal blood exhibit strong to intense reactivity $(+,+++)$ with heavier and coarser granules depositing randomly in the cytoplasm (Plate VI).

An assessment of the nonspecific esterase scores of the myeloblasts of AGL shows the level of scores to range between 49 and 88 with a mean of 75 (Table 2; Chart 6). The myeloblasts of normal bone marrow have scores between 63 and 87 with a mean of 73 (Table 2; Chart 7). These scores were judged lower than the 
nonspecific esterase scores of the monoblasts of AML and the monocytes of normal blood. The reactivity of the myeloblasts of AGL and the myeloblasts of normal blood appears as a scattering of fine granules $(+,++)$ throughout the cytoplasm with most intense localization at the nuclear hof (Plates VI,VII).

Phosphory lase Reaction. In genera1, the degree of phosphorylase activity and its intracellular localization in the primitive cells of the acute leukemias and of normal blood and bone marrow cells corresponds closely with the cytoplasmic distribution and the relative amount of preformed glycogen demonstrated by the PAS reaction (Table 2; Charts 8,9; Plates VII,VIII). Occasionally, individual blast cells from the acute leukemias show a more intense phosphorylase reaction than would be expected from their PAS reactivity.

Lactic Dehydrogenase Reaction. Lactic dehydrogenase scores in the 1ymphoblasts of ALL and the lymphocytes of normal blood are comparable. Scores in the lymphoblasts of ALL range between 86 and 157 with a mean of 117 and in the lymphocytes of normal blood 
vary between 73 and 145 with a mean of 110 (Table 2; Charts 10,11). The activity of the 1ymphoblasts of ALL shows intensities of weak, moderate, and strong $(+,++$, ++ ) and appears as fine and coarse granules localizing at the site of mitochondrial concentration with some granules depositing randomly throughout the cytoplasm (Plate VIII). Lymphocytes of normal blood exhibit a similar pattern ( $\mathrm{Plate} \mathrm{IX}$ ).

The 1actic dehydrogenase scores of the monoblasts of AML are similar to the lactic dehydrogenase scores of the 1ymphoblasts of ALL. Likewise, the lactic dehydrogenase scores of the monoblasts of AML and the monocytes of normal blood are comparable. Lactic dehydrogenase scores of monoblasts of AML range between 92 and 166 with a mean of 123 and in monocytes of normal blood range between 107 and 149 with a mean of 117 (Table 2; Charts 10,11$)$. Cytologically, the reactivity in the monoblasts of AML and the monocytes of normal blood has the same intensity $(+,+,++)$ with fine to coarse granules localizing primarily in the perinuclear cytoplasm (Plates VIII,IX). 
The lactic dehydrogenase scores in the myeloblasts of AGL are comparable to the lactic dehydrogenase scores assessed for the 1ymphoblasts of ALL and the monoblasts of AML with the lactic dehydrogenase scores varying between 107 and 157 with a mean of 121. The myeloblasts of normal bone marrow were judged to have slightly lower lactic dehydrogenase scores ranging between 72 and 128 with a mean of 91 (Table 2; Charts 10,11). The activity of the myeloblasts of AGL is of greater intensity ( + , +++ ) than that seen in the myeloblasts of normal blood in which the reactivity was weak to moderate $(+,++)$. Localization of the granules is most intense near the nuclear hof (Plate IX).

\section{DISCUSSION}

Cytochemical activity of the primitive cells of the acute leukemias has been shown by multiple cytochemical procedures. The cytochemical studies suggest that there are alterations in cellular differentiation which are reflected in the cytochemical profiles of the primitive cells. Variation in the level of scores and reaction patterns of the acid phosphatase activity, nonspecific 
esterase activity, and the Sudan black and PAS reactions observed in the present study correlates closely with the cytoplasmic and granular development and maturation exhibited by the primitive cells.

Cytologica11y, acid phosphatase and nonspecific esterase activity localizes in both azurophilic and specific granules. Correlated electron microscopic cytochemical studies reveal that these enzymes reside in the azurophilic and specific granules of human and rabbit leukocytes $17,71,136,207$ The cytological results show that the greatest acid phosphatase activity and nonspecific esterase activity appears in the monoblasts of AML with moderate activity in the myeloblasts of AGL and the least activity in the lymphoblasts of ALL. These differences in enzymatic activity indicate the possibility that there are specific varieties of the primitive cells of the acute leukemias. Morever, comparison of these results to the results of the normal controls suggests that altered enzyme patterns or impaired cytoplasmic differentiation may occur in association with the formation of azurophilic granules at an earlier time 
in cellular development. In comparing the reactions of the monoblasts of AML with the monocytes of normal blood or the reactions of the lymphoblasts of ALL with the lymphocytes of normal blood, the intensities of acid phosphatase and nonspecific esterase activities are similar indicating that the monoblasts of AML and the 1ymphoblasts of ALL may reflect altered granular deve1opment and/or cytochemical differentiation. The increased acid phosphatase activity of the myeloblasts of AGL as compared to the acid phosphatase activity of the myeloblasts of normal blood shows that similar alterations in cellular development may occur in the myeloblasts of AGL. Recent cytochemical studies and electron microscopic cytochemical evidence indicates that 1ipids localize in the mitochondria and the cytoplasmic granules of the leukocytes.10,18,87,91 The Sudan black reaction demonstrates that lipids increase with the maturation of the normal granulocytes correlating with the increase in number of the specific granules.19,87,179 The myeloblasts of AGL which show reaction patterns similar to normal myelocytes suggest the presence of numerous 
cytoplasmic granules at an earlier time in maturation. The monoblasts of AML with numerous Sudan black B reactive granules indicate that many azurophilic granules and/or mitochondria are present. The 1ymphoblasts of ALL exhibit only minimal Sudan black reactions and closely resemble the reaction seen in norma1 1ymphocytes. Such observations suggest the possibility of aberrant cellular differentiation of the granules and/or mitochondria of the developing primitive cells.

The higher PAS scores of the lymphoblasts of ALL as' compared to the monoblasts of AML and the myeloblasts of AGL confirm the results of other investigations.87,161 The large granular clumps of glycogen often seen in lymphoblasts of ALL, the particulate glycogen observed in myeloblasts of AGL, and the more frequent occurrence of moderately coarse granules without diffuse coloration seen in monoblasts of AML may reflect an alteration in cellular metabolism since large aggregates of glycogen in normal 1ymphocytes or particulate glycogen in normal myeloblasts cannot be observed. The present study and other evidence $87,163,214$ suggests that the activity of 
phosphorylase corresponds to the distribution of preformed glycogen. The increased levels of phosphorylase activity that were found parallel closely the increased levels of preformed glycogen. These results tend to demonstrate that the increased levels of glycogen may result from the increase in the levels of phosphorylase activity。

The intracellular 1ocalization of lactic dehydrogenase (LDH) activity appears to reside in both the mitochondria and the cytoplasm of the leukocytes.10,20,87 Cytologically, the distribution of the $\mathrm{LDH}$ reactive granules in the primitive cells of the acute leukemias tends to follow the distribution of the mitochondria seen in normal leukocytes. Intragranular deposits of LDH activity are also noted. Recent biochemical observations $34,54,60,61,156,158,177$ indicate that $L D H$ activity in various tissues exists in multiple molecular forms with five isoenzyme patterns. The isoenzyme patterns of the acute leukemias are identical with a predominance of LDH- 3 activity which is similar to patterns obtained from fetal tissues 156,177 and immature granulocytes. 53,54 
The cytochemical levels of LDH activity of the primitive cells were judged to be similar and agree with the biochemical results suggesting that at a cellular leve1 the LDH activity in the primitive cells is comparable in ALL, AML, and AGL. The levels of lactic dehydro-.. genase scores of the primitive cells of the acute leukemias are slightly higher than comparable normal controls and agree with biochemical investigations which indicate that the concentration of the dehydrogenases is increased in leukemic leukocytes. ${ }^{29}$

The primitive cells of the acute leukemias are nonreactive to the alkaline phosphatase reaction. However, in assessing the scores of the neutrophils of the acute leukemias, there is sufficient variation in the scores to aid in a differential diagnosis of the acute leukemias. The current results agree with other evidence 85,87 which show high alkaline phosphatase scores in ALL, intermediate scores in AML, and low scores in AGL. Cytochemistry, at both the light and the electron microscopic levels, reveals that alkaline phosphatase activity localizes in the specific granules of 
the mature neutrophils of the granulocytes. $10,17,91,136,207$ The altered levels of alkaline phosphatase activity observed in the mature neutrophils of AGL which show variations in the size and number of the specific granules may be compatible with a qualitative and quantitative difference in the specific granules that may have occurred during differentiation. The higher levels of alkaline phosphatase activity seen in the mature neutrophils of ALL and AML are not specifically attributable to the cellular lineage involved or an indication of granulocytic proliferation. It may indicate the normal response of the neutrophils with increased enzyme activity to infections and stress situations. $87,193,197$ The primitive cells of the patients in the acute phase of chronic granulocytic leukemia do not demonstrate significantly different enzyme reaction patterns of the acid phosphatase, nonspecific esterase, and lactic dehydrogenase activities or the Sudan black B reaction as compared to the primitive cells of untreated patients with AGL. 
Biochemical analysis of the primitive cells of the acute leukemias demonstrates low levels of alkaline phosphatase and acid phosphatase activity $30,31,195,217$ and normal levels of esterase and lipase activity. 80,194 Investigations of glucose metabolism ${ }^{29}$ indicate that leukemic leukocytes utilize the phosphogluconate pathway more than normal leukocytes. This is attributed to their deficiencies of hexokinase. Also, the same study revealed that the dehydrogenases were present in greater concentration than was necessary for their metabolic activity. ${ }^{29}$ The low biochemical alkaline phosphatase activity is attributed to the low percentage of mature myeloid cells. Indications that there is more than one acid phosphatase ${ }^{23}$ suggests the possibility that the biochemical methods may be demonstrating different enzyme reactions. In making chemical and cytochemical comparisons of abnormal cells in which various enzymes may vary or exhibit the same levels of activity, it may be advantageous to study intact cells which may possess important metabolic alterations that 
may have resulted from aberrant organizations within the ce11. 217

Recent evidence with the use of thymidine-labelled cel1s ${ }^{64,65}$ suggests that the bone marrow of patients with acute leukemias possesses two primitive cell populations, large primitive cells with proliferative ability and sma11 primitive ce1ls that are gradually losing the ability to proliferate. From this evidence it is postulated that the major cell defect in the acute leukemias is the inability for differentiation and maturation. Although the purpose of the present study was not to differentiate between two primitive cell populations of the bone marrows of the acute leukemias, an examination of the illustrations (Plate I, Figures 1,2,3,4; Plate II, Figures 6,7; Plate III, Figures 10,11; Plate IV, Figures 14,15; Plate VII, Figure 26; Plate VIII, Figures 31,32) tends to support cytochemically the postulation that dual primitive cell populations may exist. These observations show the possibility of intermediate cell forms between the larger and smaller primitive cells. Moreover, many of 
the larger primitive cells demonstrate increased amounts of enzymatic reactive materials which suggests enhanced proliferative capability. Our cytochemical evidence, however, indicates that the primitive cells of the acute leukemias, which exhibit morphological and cytochemical variations, can be distinguished as specific types ${ }^{10}$ and are not modifications of a single precursor cell. The acid phosphate activity, the nonspecific esterase activity, and the Sudan black reaction show sufficient variation in their scores and reaction patterns to indicate the existance of several varieties of stem ce11s. The dissimilarity of the PAS reactive material and scores in the lymphoblasts of ALL, the monoblasts of AML, and the myeloblasts of AGL suggests the possibility of differences in these primitive cells.

\section{SUMMARY}

Blood and bone marrow films of seventy-one patients with acute leukemias and nineteen normal controls were evaluated morphologically by using Wright's stain and cytochemically by using seven cytochemical reactions: the periodic acid-Schiff reaction for the identification 
of glycogen and glycoprotein, the Sudan black B reaction for 1ipids, the Goldberg and Barka method for acid phosphatase activity, naphthol AS-MX phosphate-Fast blue RR procedure for the alkaline phosphatase reaction, the naphthol AS acetate-Fast blue $B B$ reaction for the demonstration of nonspecific esterase activity, the modified method of Erankö and Palkama for phosphorylase reactivity, and the modified technique of Quaglino and Hayhoe for the localization of lactic dehydrogenase activity.

A semiquantitative scoring method was used for estimating the intensity of the cytochemical enzyme reactions of the primitive cells of patients with acute leukemias and blood and bone marrow cells of normal controls. Alkaline phosphatase activity was scored by counting mature neutrophils of the blood and bone marrow cells of patients with acute leukemias and normal controls.

Variations in the level of scores and reaction patterns of the acid phosphatase activity, nonspecific esterase reactivity, the alkaline phosphatase activity, and the Sudan black and PAS reactions provide additional 
differential criteria for the separation and classification of the acute leukemias.

These cytochemical studies suggest that alterations may exist in cellular differentiation which are reflected in the cytochemical profiles of the primitive cells of acute leukemias. Altered enzyme patterns exhibited by the primitive cells correlate closely with the degree of cytoplasmic and granular development and/or maturation. Morphological and cytochemical variations indicate that the primitive cells of the acute Ieukemias can be identified and represent specific varieties of stem cells. 
Table 1.--Cytological Characteristics in Wright's Stain of the Cells of Blood and Bone Marrow of Patients with Acute Leukemias

\begin{tabular}{|c|c|c|}
\hline $\begin{array}{l}\text { Acute } \\
\text { Lymphocytic } \\
\text { Leukemia }\end{array}$ & $\begin{array}{l}\quad \text { Acute } \\
\text { Monocytic } \\
\text { Leukemia }\end{array}$ & $\begin{array}{l}\text { Acute } \\
\text { Granulocytic } \\
\text { Leukemia }\end{array}$ \\
\hline $\begin{array}{l}\text { Predominant cells are } \\
\text { lymphoblasts. } \\
\text { Round or oval neucleus. } \\
\text { Coarse, deeply staining } \\
\text { nuclear chromatin. } \\
\text { Chromatin more compact } \\
\text { around edges of nucleus } \\
\text { and nucleoli. } \\
\text { l-2 nucleoli. } \\
\text { Clear zone around nucleus. } \\
\text { Cytoplasm basophilic; } \\
\text { scant; contains no granules. } \\
\text { Vacuolation can be marked. } \\
\text { Mature lymphocytes usually } \\
\text { present which contain a } \\
\text { few azurophilic granules. }\end{array}$ & $\begin{array}{l}\text { Predominant cells are } \\
\text { promonocytes or mono- } \\
\text { blasts. } \\
\text { Nuclei irregular in } \\
\text { shape; often appear } \\
\text { twisted and folded. } \\
\text { Fine, reticular } \\
\text { chromatin. } \\
\text { l-2 large nucleoli. } \\
\text { Cytoplasm abundant; } \\
\text { grey-blue with fine, } \\
\text { reddish-lilac } \\
\text { azurophilic granules. } \\
\text { Cell boundaries } \\
\text { irregular. } \\
\text { Extensive vacuolation. }\end{array}$ & $\begin{array}{l}\text { Predominant cells are } \\
\text { myeloblasts. } \\
\text { Round or oval nuclei } \\
\text { with fine chromatin } \\
\text { network. } \\
\text { Usually } 2-5 \\
\text { prominent nucleoli. } \\
\text { Cytoplasm deep blue; } \\
\text { scant; possesses few } \\
\text { or no azurophilic } \\
\text { granules. } \\
\text { Cytoplasmic vacuo- } \\
\text { lation rare. } \\
\text { Progranulocytes } \\
\text { nearly always } \\
\text { present. }\end{array}$ \\
\hline
\end{tabular}


Table 2.--Mean Scores of Cytochemical Reactions of Patients with Acute Leukemias and Compatible Normal Controls

\begin{tabular}{|c|c|c|c|c|c|c|}
\hline $\begin{array}{c}\text { Acute } \\
\text { Leukemias }\end{array}$ & $\begin{array}{c}\text { Number } \\
\text { of } \\
\text { Patients }\end{array}$ & PAS & Phosphorylase & $\begin{array}{c}\text { Acid } \\
\text { Phosphatase }\end{array}$ & $\begin{array}{c}\text { Nonspecific } \\
\text { Esterase }\end{array}$ & $\begin{array}{c}\text { Lactic } \\
\text { Dehydrogenase }\end{array}$ \\
\hline ALL & 29 & $\begin{array}{c}134 \\
(62-214)\end{array}$ & $\begin{array}{c}120 \\
(52-185)\end{array}$ & $\begin{array}{c}90 \\
(60-131)\end{array}$ & $\begin{array}{c}71 \\
(38-101)\end{array}$ & $\begin{array}{c}117 \\
(86-157)\end{array}$ \\
\hline AML & 23 & $\begin{array}{c}88 \\
(48-121)\end{array}$ & $\begin{array}{c}84 \\
(38-129\end{array}$ & $\begin{array}{c}128 \\
(93-155)\end{array}$ & $\begin{array}{c}144 \\
(120-185)\end{array}$ & $\begin{array}{c}\text { i23 } \\
(92-166)\end{array}$ \\
\hline AGL & 19 & $\begin{array}{c}53 \\
(28-102)\end{array}$ & $\begin{array}{c}46 \\
(28-83)\end{array}$ & $\begin{array}{c}120 \\
(96-143)\end{array}$ & $\begin{array}{c}75 \\
(49-88)\end{array}$ & $\begin{array}{c}121 \\
(107-157)\end{array}$ \\
\hline $\begin{array}{l}\text { Normal } \\
\text { Controls }\end{array}$ & $\begin{array}{c}\text { Number } \\
\text { of } \\
\text { Controls }\end{array}$ & PAS & Phosphorylase & $\begin{array}{c}\text { Acid } \\
\text { Phosphatase }\end{array}$ & $\begin{array}{l}\text { Nonspecific } \\
\text { Esterase }\end{array}$ & $\begin{array}{c}\text { Lactic } \\
\text { Dehydrogenase }\end{array}$ \\
\hline Lymphocyte & 21 & $\begin{array}{c}39 \\
(26-62)\end{array}$ & $\begin{array}{c}38 \\
(24-60)\end{array}$ & $\begin{array}{c}94 \\
(58-120)\end{array}$ & $\begin{array}{c}68 \\
(42-95)\end{array}$ & $\begin{array}{c}110 \\
(73-145)\end{array}$ \\
\hline Monocyte & 12 & $\begin{array}{c}74 \\
(47-105)\end{array}$ & $\begin{array}{c}71 \\
(45-105)\end{array}$ & $\begin{array}{c}132 \\
(108-150)\end{array}$ & $\begin{array}{c}140 \\
(105-149)\end{array}$ & $\begin{array}{c}117 \\
(107-149)\end{array}$ \\
\hline Myeloblast & 13 & $\begin{array}{c}35 \\
(21-67)\end{array}$ & $\begin{array}{c}33 \\
(20-47)\end{array}$ & $\begin{array}{c}86 \\
(68-99)\end{array}$ & $\begin{array}{c}73 \\
(63-87)\end{array}$ & $\begin{array}{c}91 \\
(72-128)\end{array}$ \\
\hline
\end{tabular}

Abbreviations: ALL=acute lymphocytic leukemia; AML=acute monocytic leukemias; $A G L=a c u t e$ granulocytic leukemia; range of scores in parentheses. 
Table 3.--Mean Scores of Alkaline Phosphatase Activity of Mature Neutrophils of Patients with Acute Leukemias and Normal Controls

Acute Leukemias Number of Patients Mean Scores of APA

\begin{tabular}{rcc} 
ALL & 22 & $\begin{array}{c}180 \\
(100-272) \\
\text { AML }\end{array}$ \\
AGL & 15 & $\begin{array}{c}91 \\
(35-157) \\
\end{array}$ \\
& 13 & $\begin{array}{c}25 \\
(9-44)\end{array}$ \\
\hline Controls & Number of Controls & Mean Scores of APA \\
\hline Norma1 & 17 & $\begin{array}{c}82 \\
(60-156)\end{array}$ \\
\hline
\end{tabular}

Abbreviations: ALIFacute lymphocytic leukemia; AML=acute monocytic leukemia; AGL =acute granulocytic

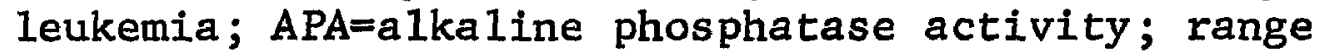
of scores in parentheses. 
Chart 1.--PAS scores of the primitive cells of patients with acute leukemias. 


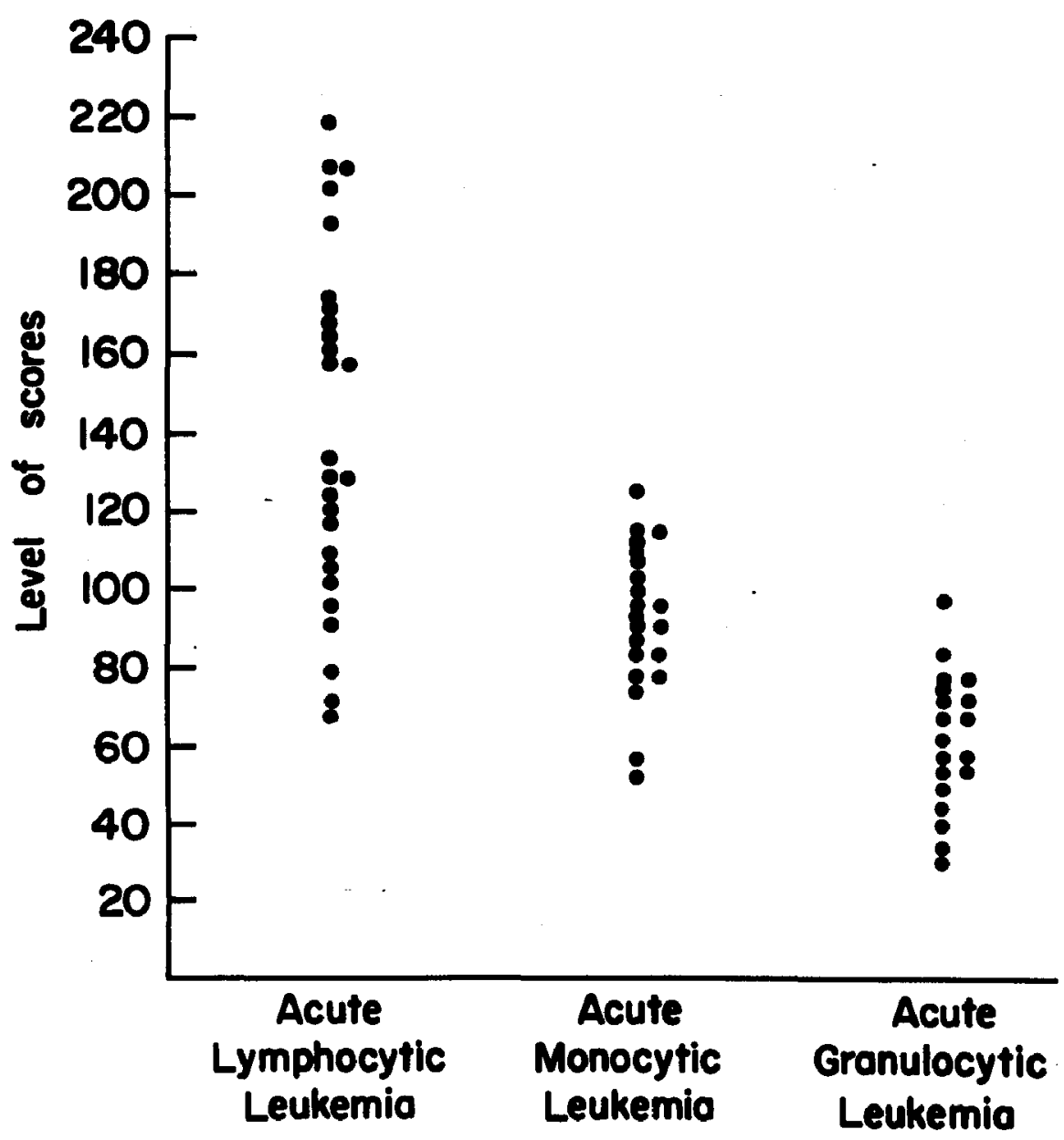

CHART 1 
Chart 2.--PAS scores of the cells of blood and bone marrow of normal controls. 


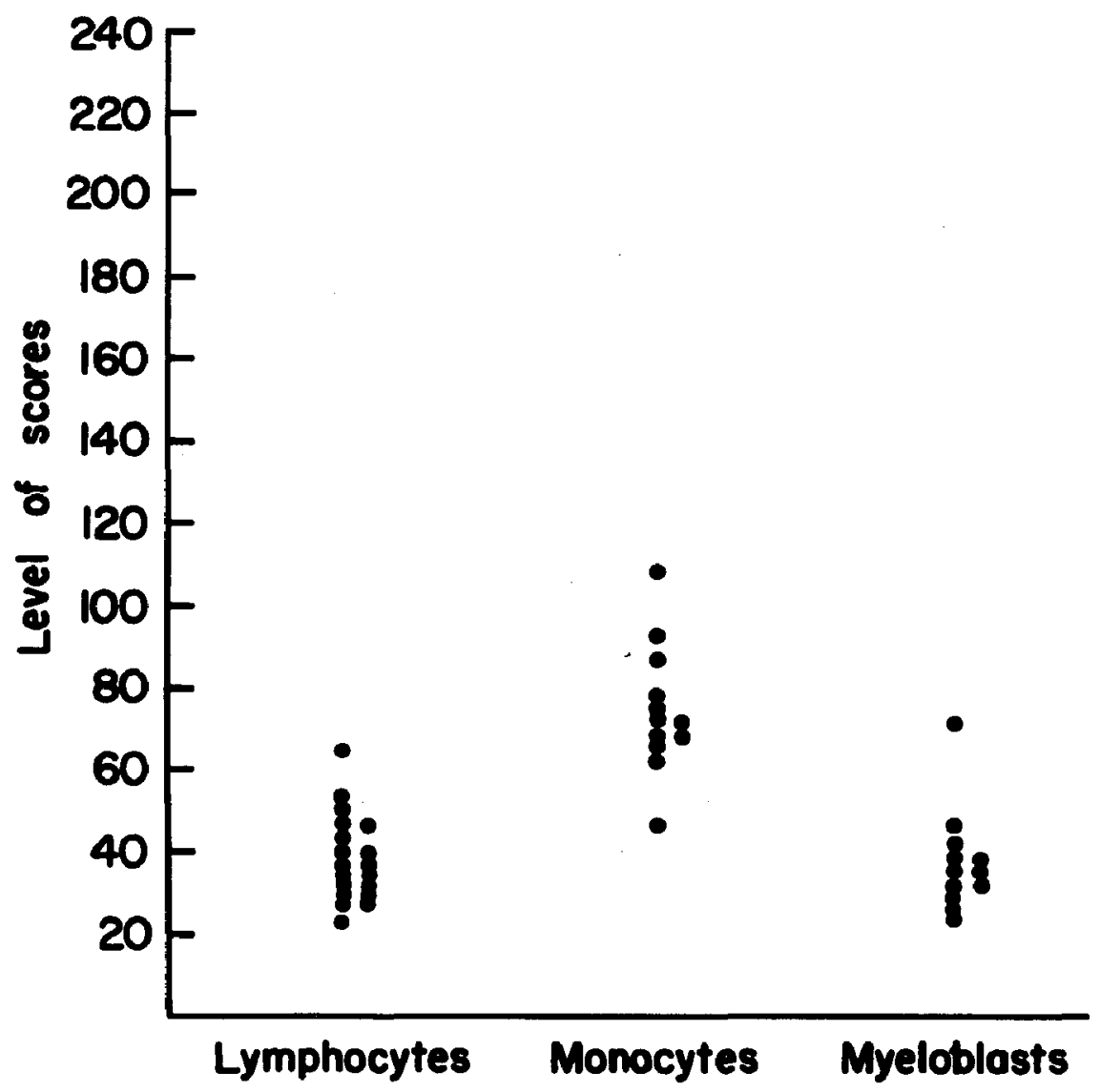

CHART 2 
Chart 3.--Acid phosphatase scores of the primitive cells of patients with acute leukemias. 


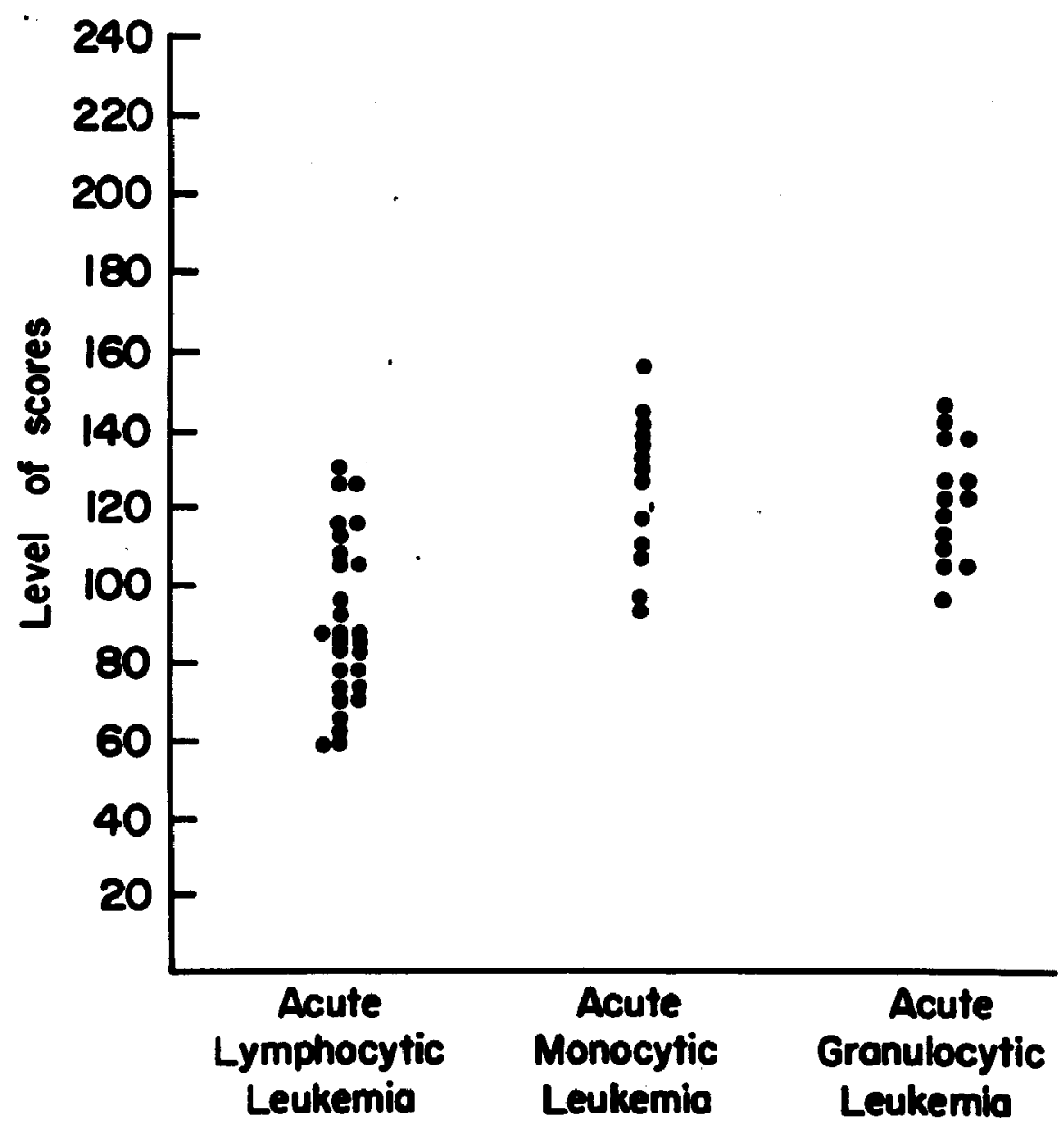

CHART 3 
Chart 4.--Acid phosphatase scores of the cells of blood and bone marrow of normal controls. 


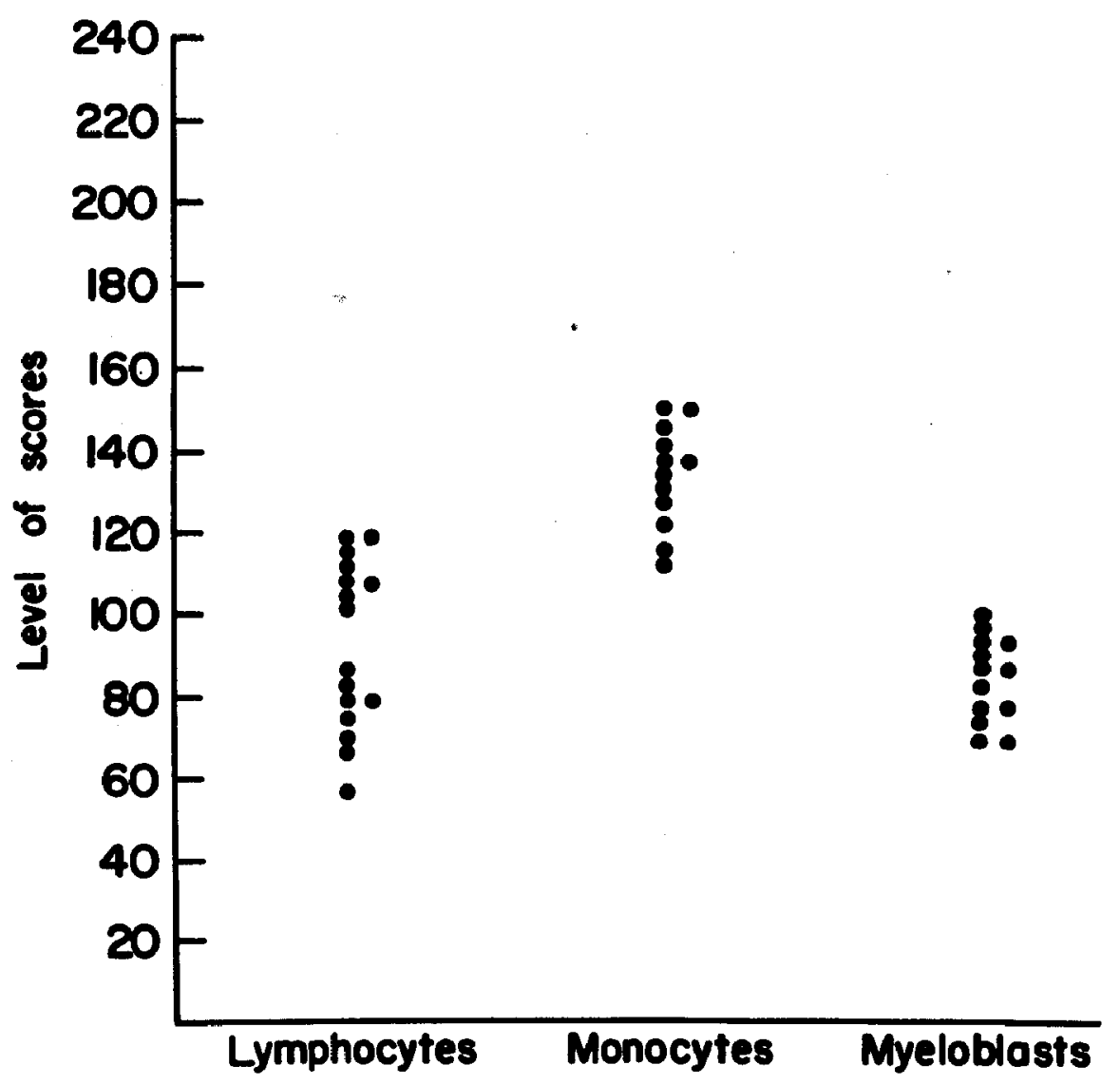

CHART 4 
Chart 5.--Alkaline phosphatase scores of the mature neutrophils of patients with acute leukemias and of normal controls. 


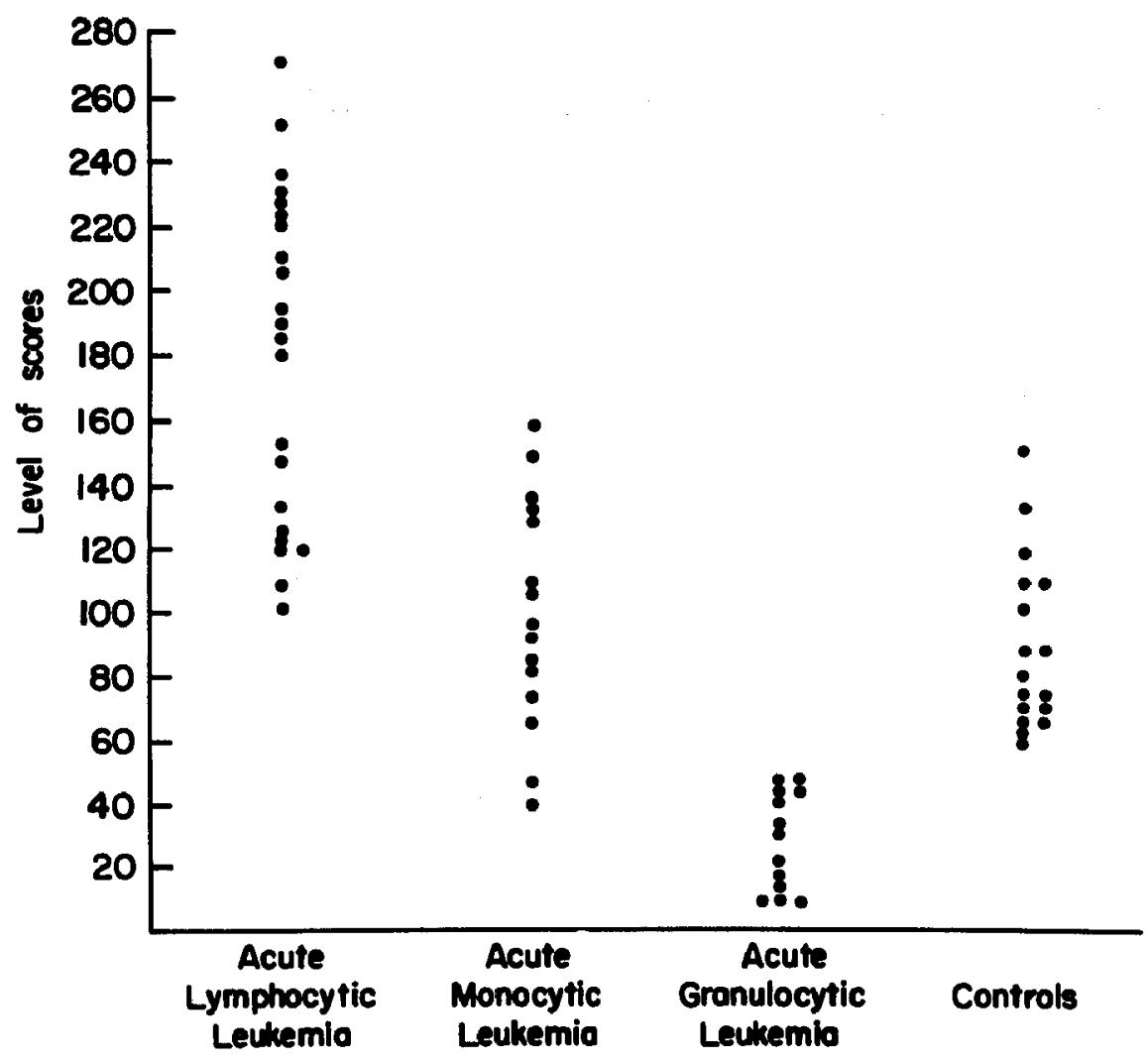

CHART 5 
Chart 6.--Nonspecific esterase scores of the primitive cells of patients with acute leukemias. 


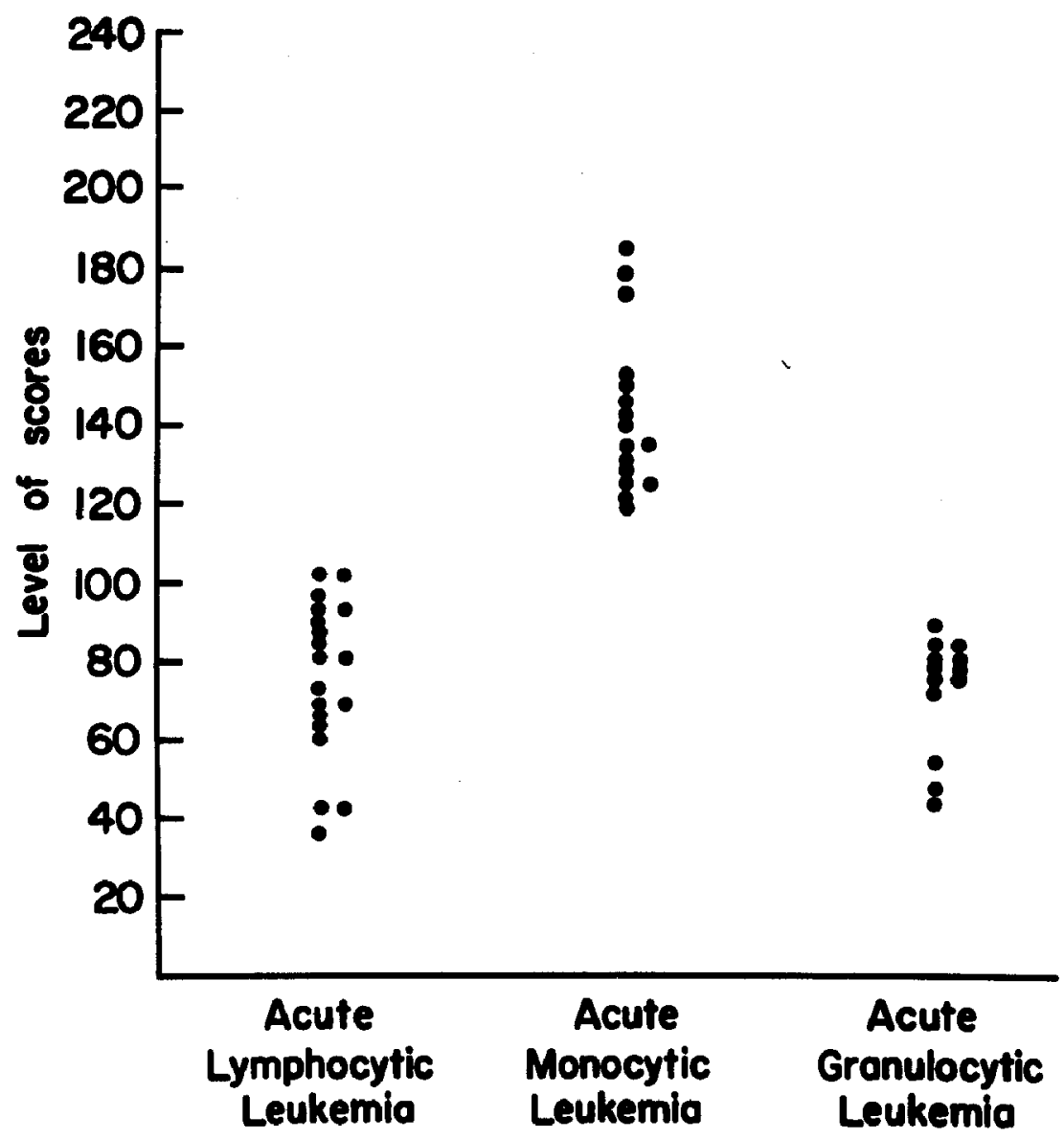

CHART 6 
Chart 7.--Nonspecific esterase scores of the cells of blood and bone marrow of normal controls. 


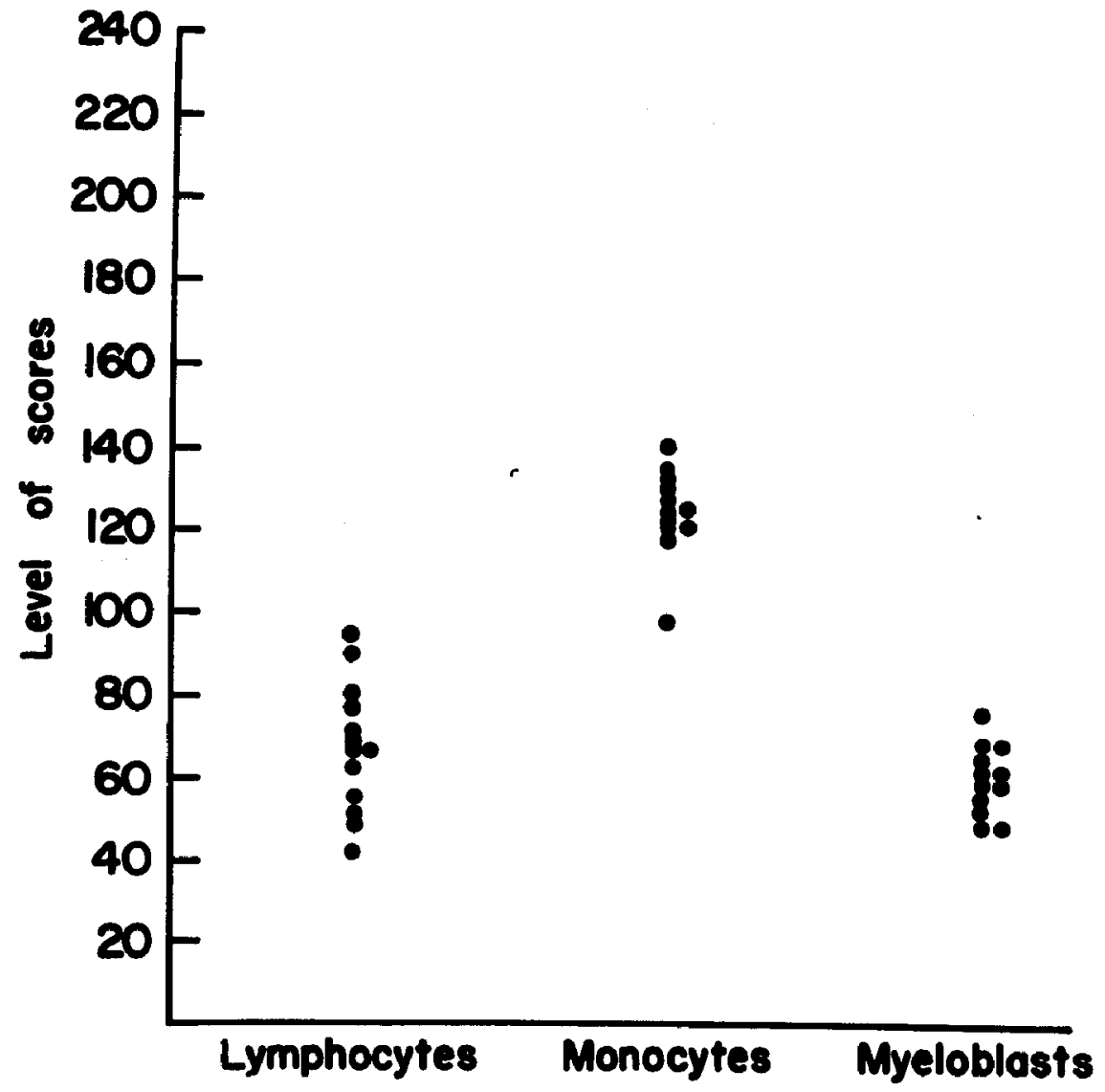

GRART 7 
Chart 8,--Phosphorylase scores of the primitive cells of patients with acute leukemias. 


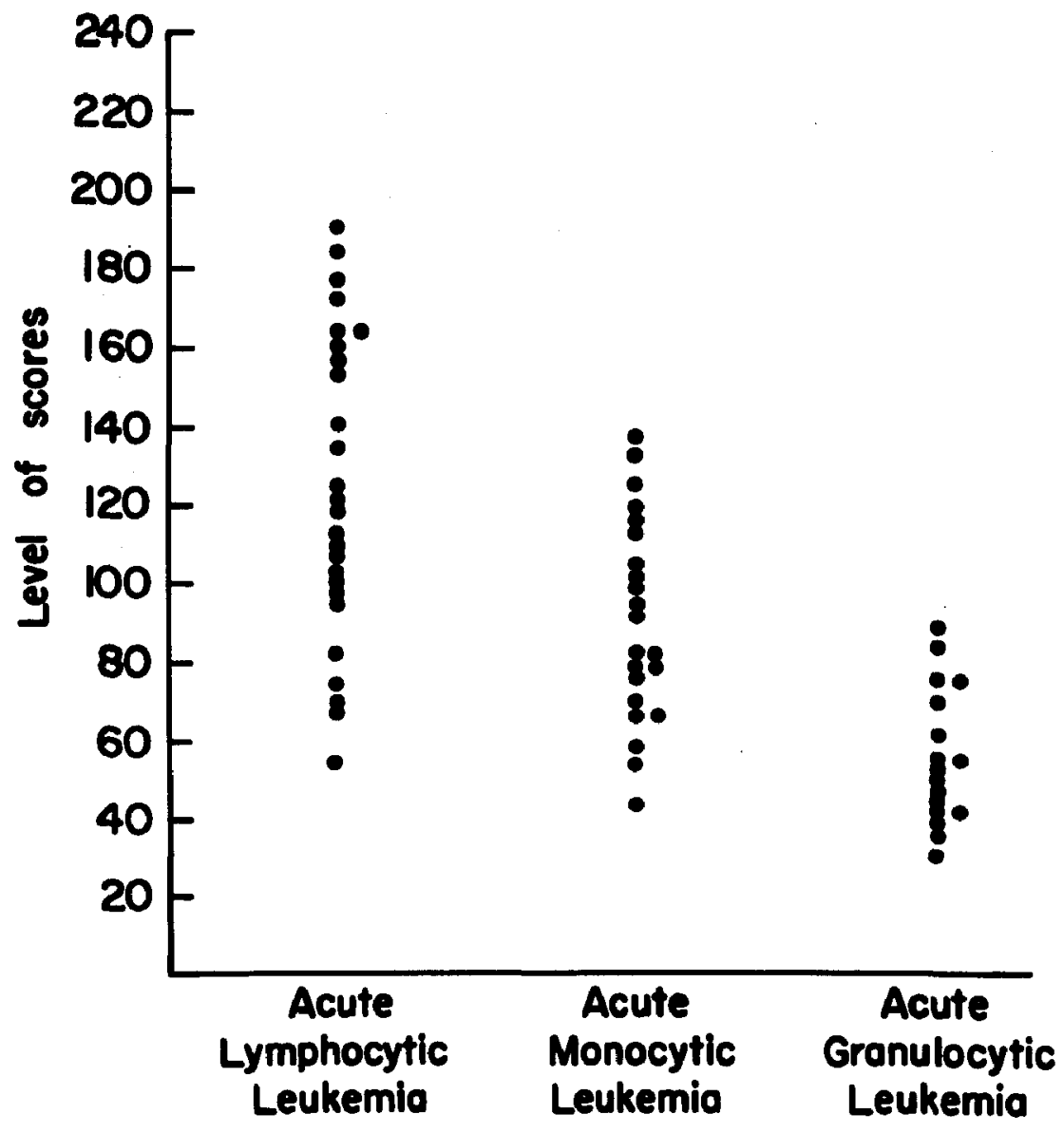

CHART 8 
Chart 9.--Phosphorylase scores of the cells of blood and bone marrow of normal controls. 


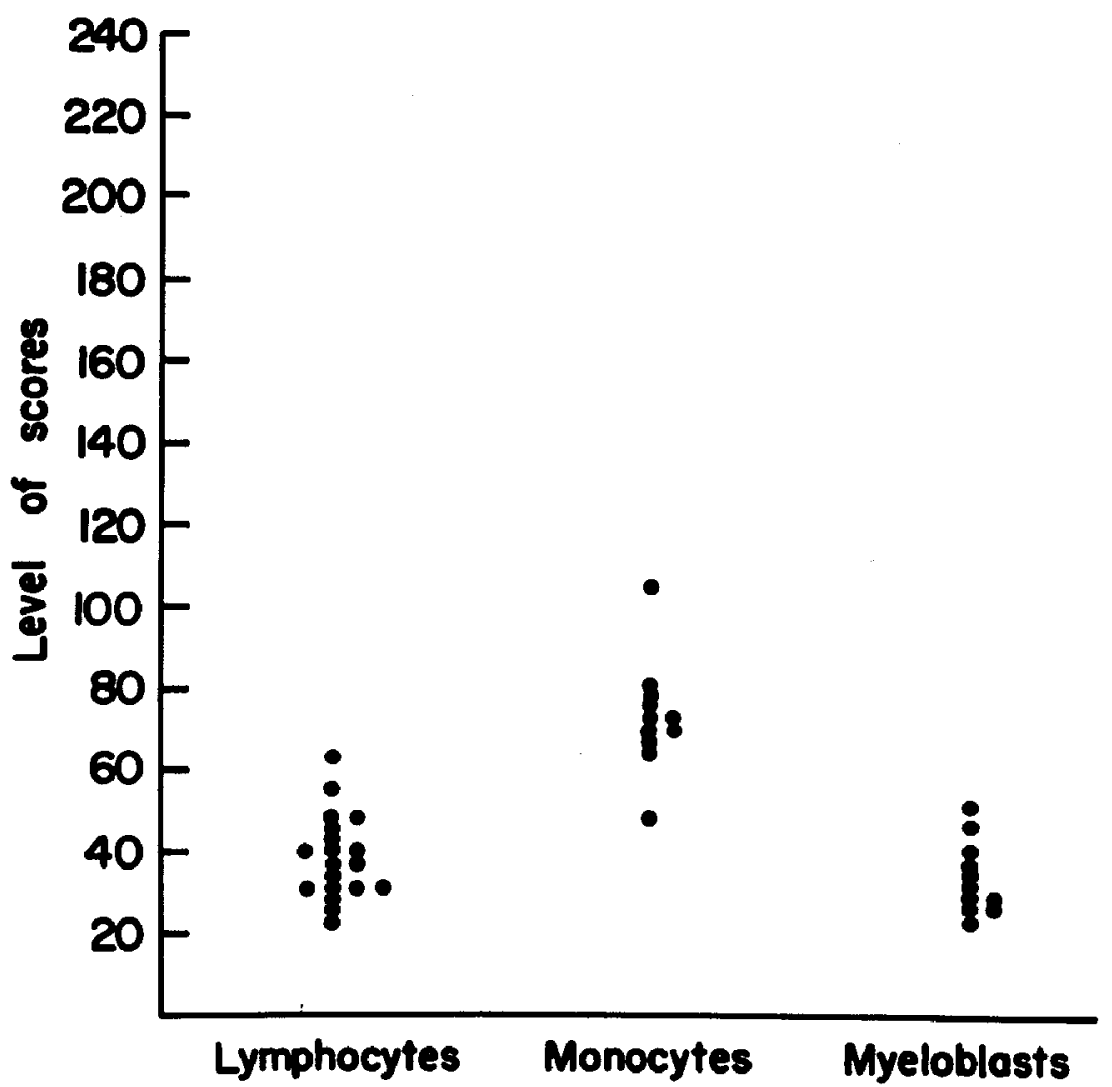

CHART 9 
Chart 10.--Lactic dehydrogenase scores of the primitive cells of patients with acute leukemias. 


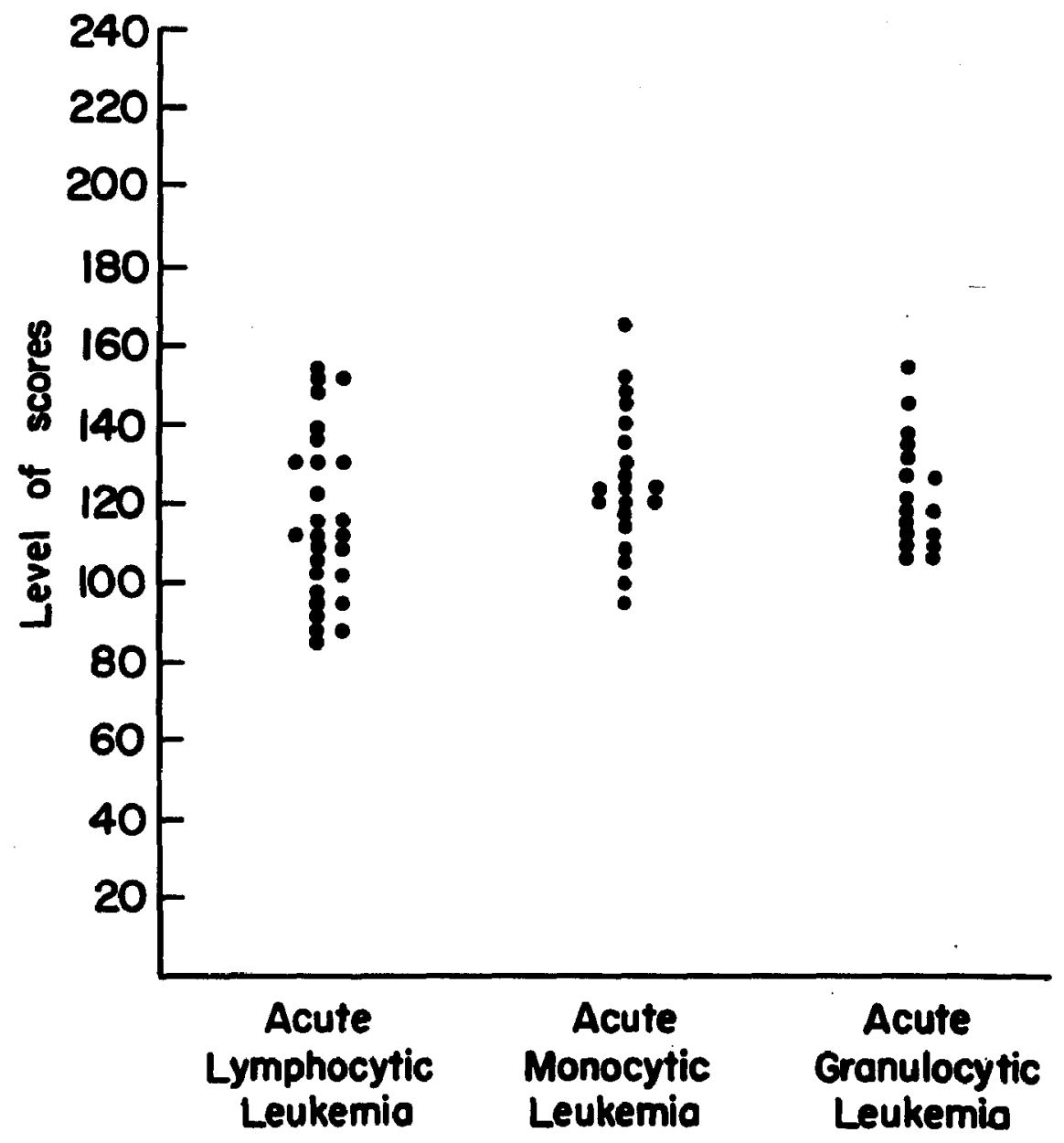

CHART 10 
Chart 11.--Lactic dehydrogenase scores of the cells of blood and bone marrow of normal controls. 


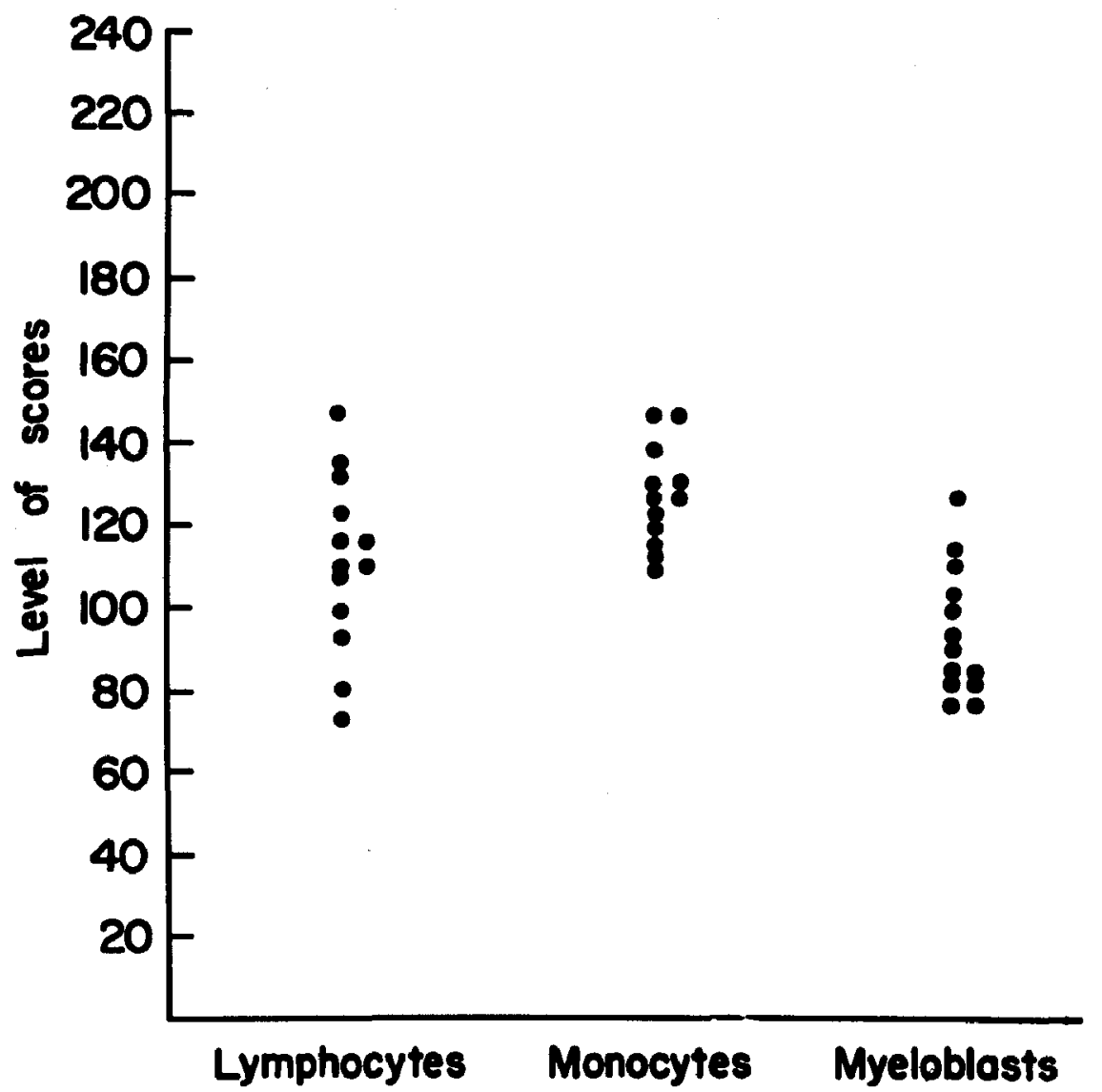

CHART 11 


\section{Legend for Plate 1.}

Fig. 1.--Wright's stain showing 1ymphoblasts from ALL. X1500

Fig. 2.--Wright's stain showing myeloblasts from AGL。 X1500

Fig. 3.--Wright's stain showing monoblasts from acute myelomonocytic leukemia. X1500

Fig. 4.--Wright's stain showing monoblasts from AML. X1500 


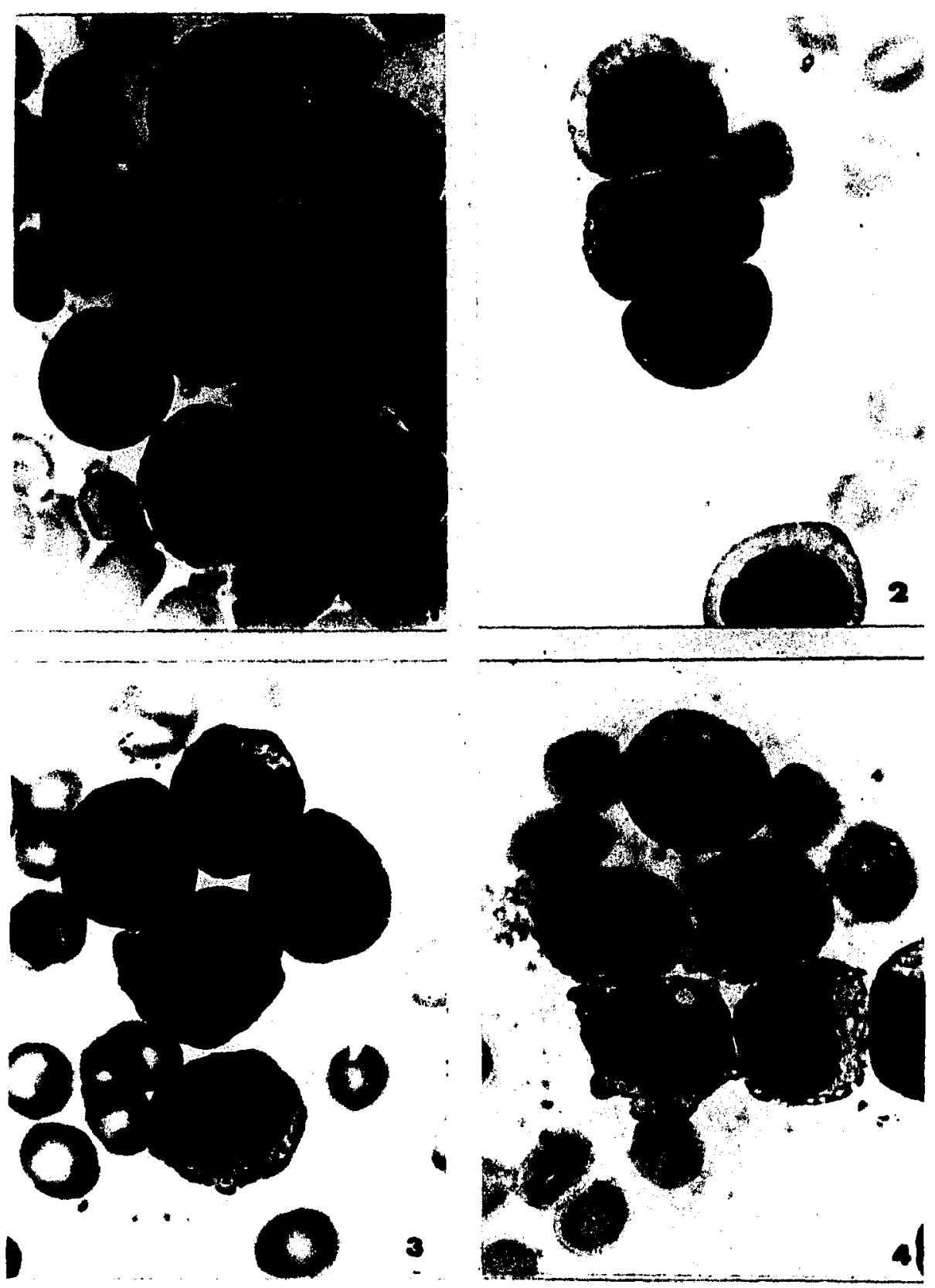

PLATE I 
Legend for Plate II.

Fig. 5.--PAS activity in 1ymphoblasts from ALL with fine and coarse granules and clumps of reactive material. X1500

Fig. 6.--Similar to Figure 5. PAS activity in lymphoblasts from ALL. X1500

Fig. 7.--PAS reaction in monoblasts from AML showing fine and coarse granules without diffuse staining. $\mathrm{X} 1600$

Fig. 8.--PAS activity in a myeloblast from AGL showing diffuse staining. $\mathrm{X} 1500$ 


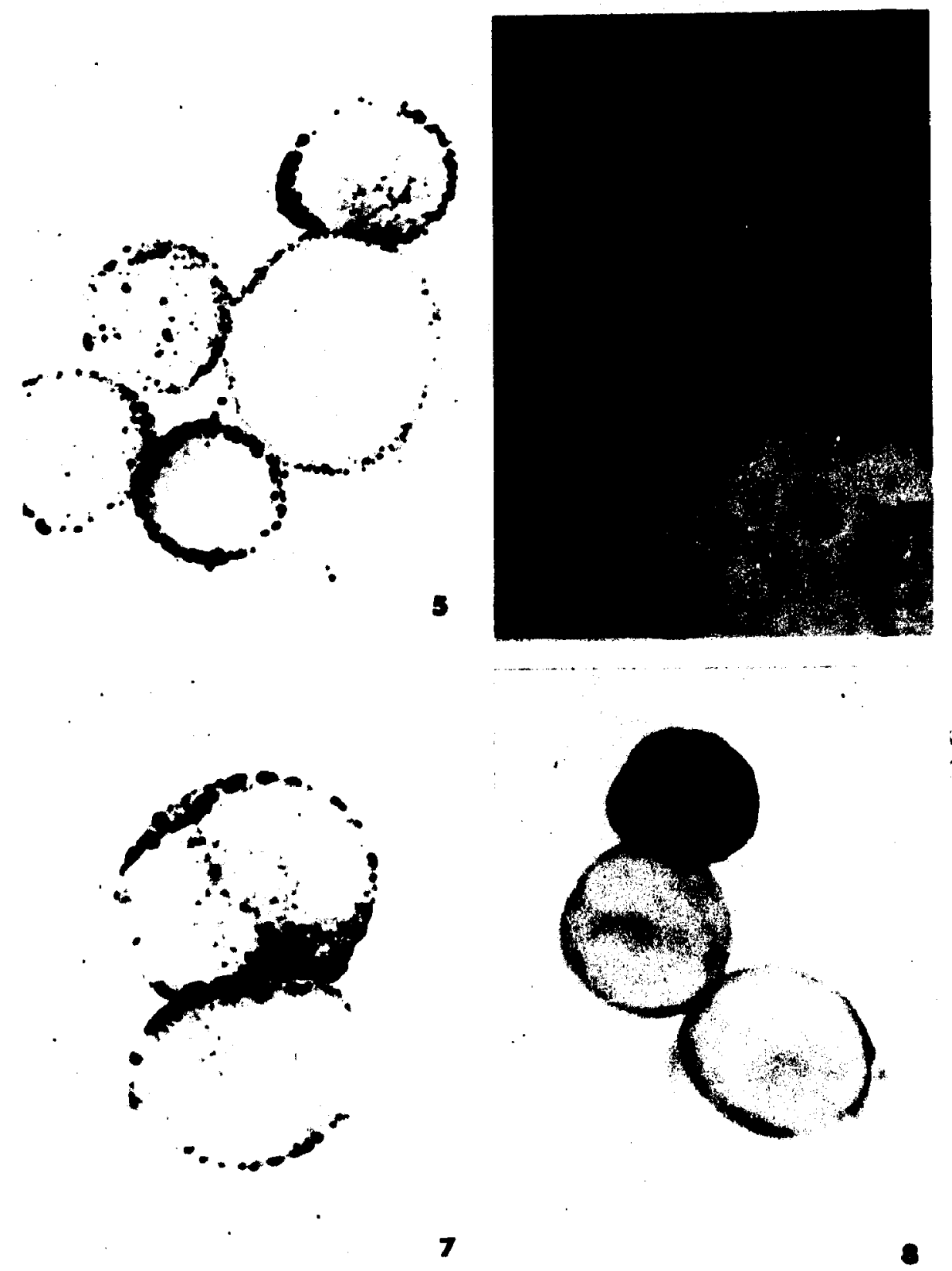

PLATE II 
Legend for Plate III.

Fig. 9.--PAS activity in a normal 1ymphocyte from peripheral blood showing moderately coarse granules near the periphery of the cytoplasm. X1500

Fig. 10.--Sudan black reaction in 1ymphoblasts from ALL showing a few reactive granules. A neutrophil demonstrates intense reactivity. X1600

Fig. 11.--Sudan black reaction in monoblasts from AML showing fine to moderately coarse granules scattered throughout the cells. X1500

Fig. 12.--Sudan black reaction in a myelocyte from normal bone marrow showing intense activity localizing near the nuclear hof. X1500 

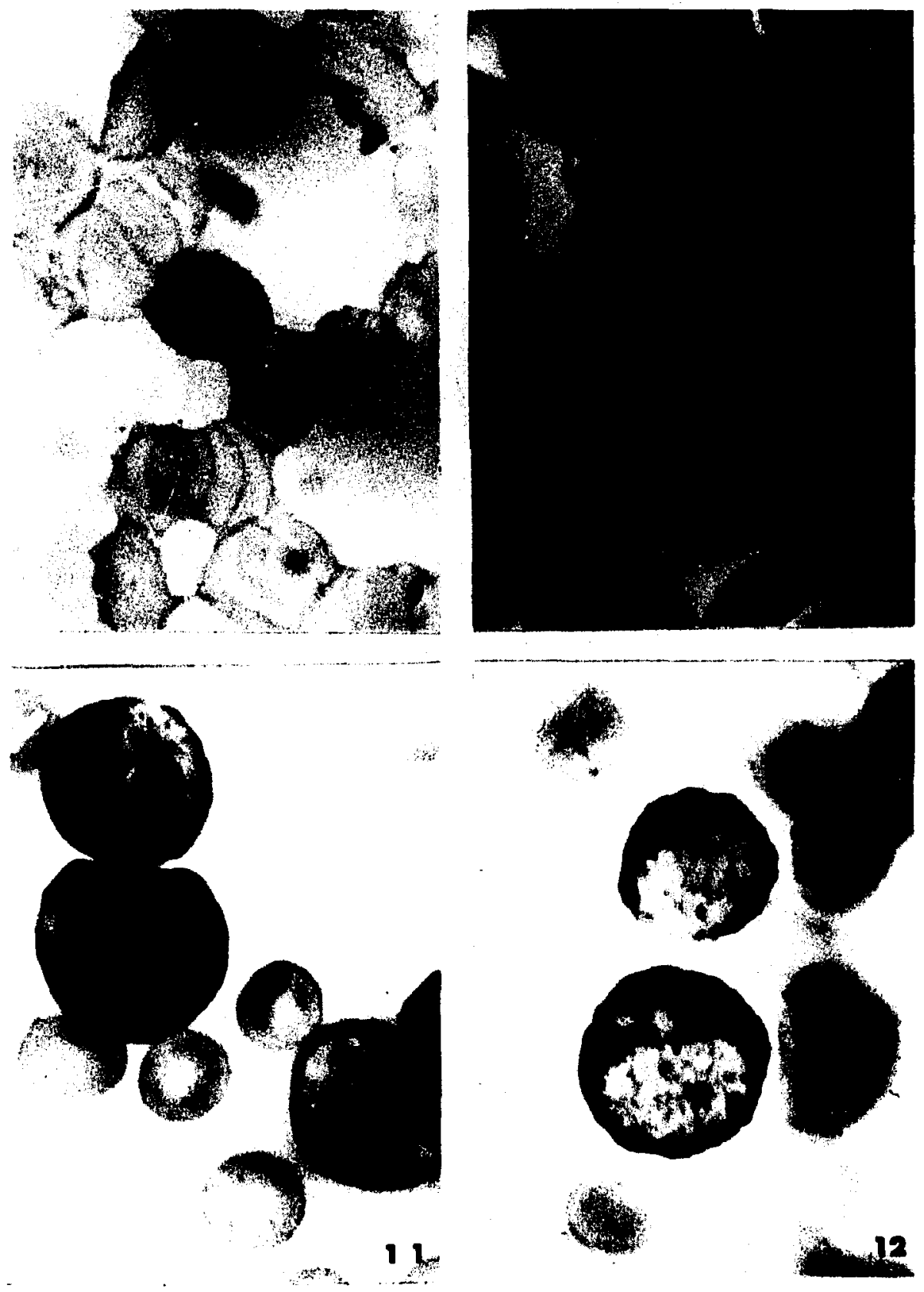

PLATE III 
Legend for Plate IV.

Fig. 13.--Acid phosphatase activity in two lymphoblasts from ALI showing small areas of reactivity near the nuclear hof. X1500

Fig. 14.--Similar to Figure 13. Acid phosphatase activity in 1ymphoblasts from ALL. X1500

Fig. 15.--Granular localization of acid phosphatase activity in monoblasts from AML. X1500

Fig. 16.--Acid phosphatase activity in a myeloblast from AGL showing reactive granules near the periphery of the cytoplasm. X1500 

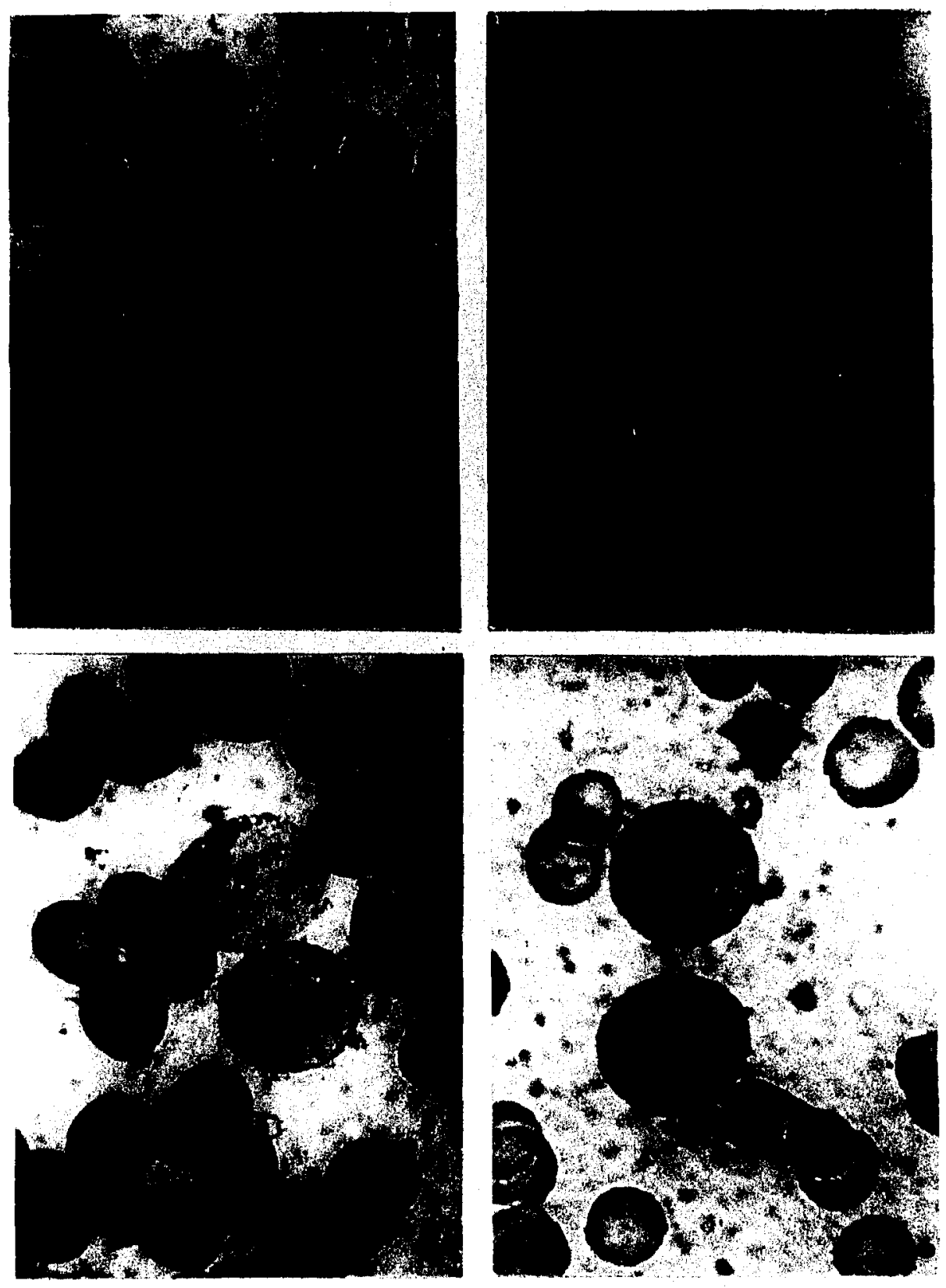

PLATE IV 


\section{Legend for Plate $\mathrm{V}$.}

Fig. 17.--Acid phosphatase activity in a normal lymphocyte showing several small areas of reactivity.

Fig. 18.--Strong acid phosphatase activity in a monocyte from normal peripheral blood. X1500

Fig.19.--Sma11 areas of acid phosphatase activity in a myeloblast from normal bone marrow localizing near the nuclear hof. X1500

Fig. 20.--Nonspecific esterase activity in a lymphoblast from ALL showing reaction granules near the nuclear hof. X1500 


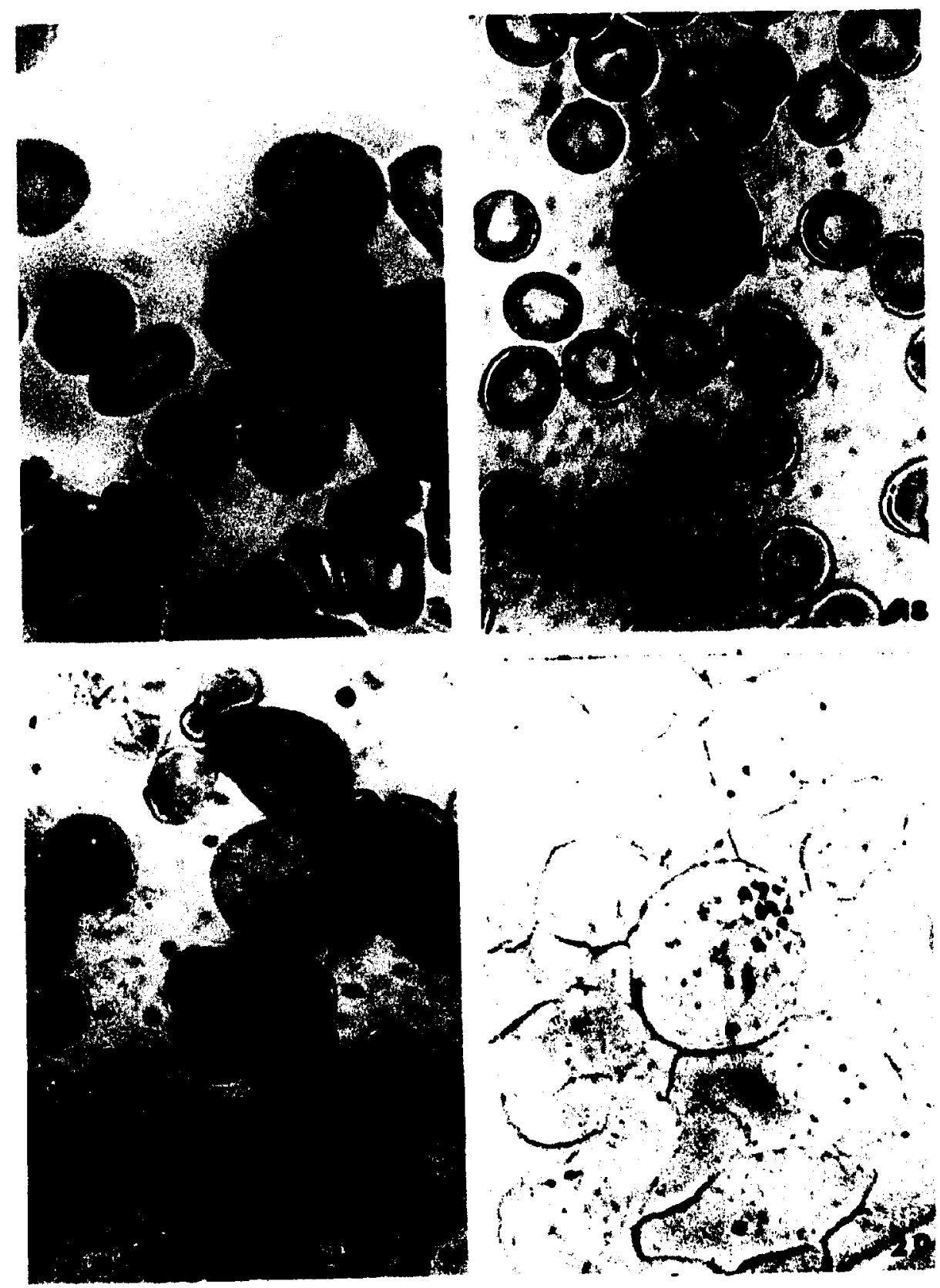

PLATE V 
Legend for Plate VI.

Fig. 21.--Strong nonspecific esterase activity in monoblasts from AML. X1500

Fig. 22.--Similar to Figure 21. Nonspecific esterase activity in monoblasts from AML. X1500

Fig.23.--Nonspecific esterase activity in a myeloblast of AGL. Fine and moderately coarse granules are deposited around the periphery of the cytoplasm but are most numerous near the nuclear hof. X1500

Fig. 24.--Nonspecific esterase activity in a normal monocyte showing coarse granules depositing throughout the ce11. X1500 


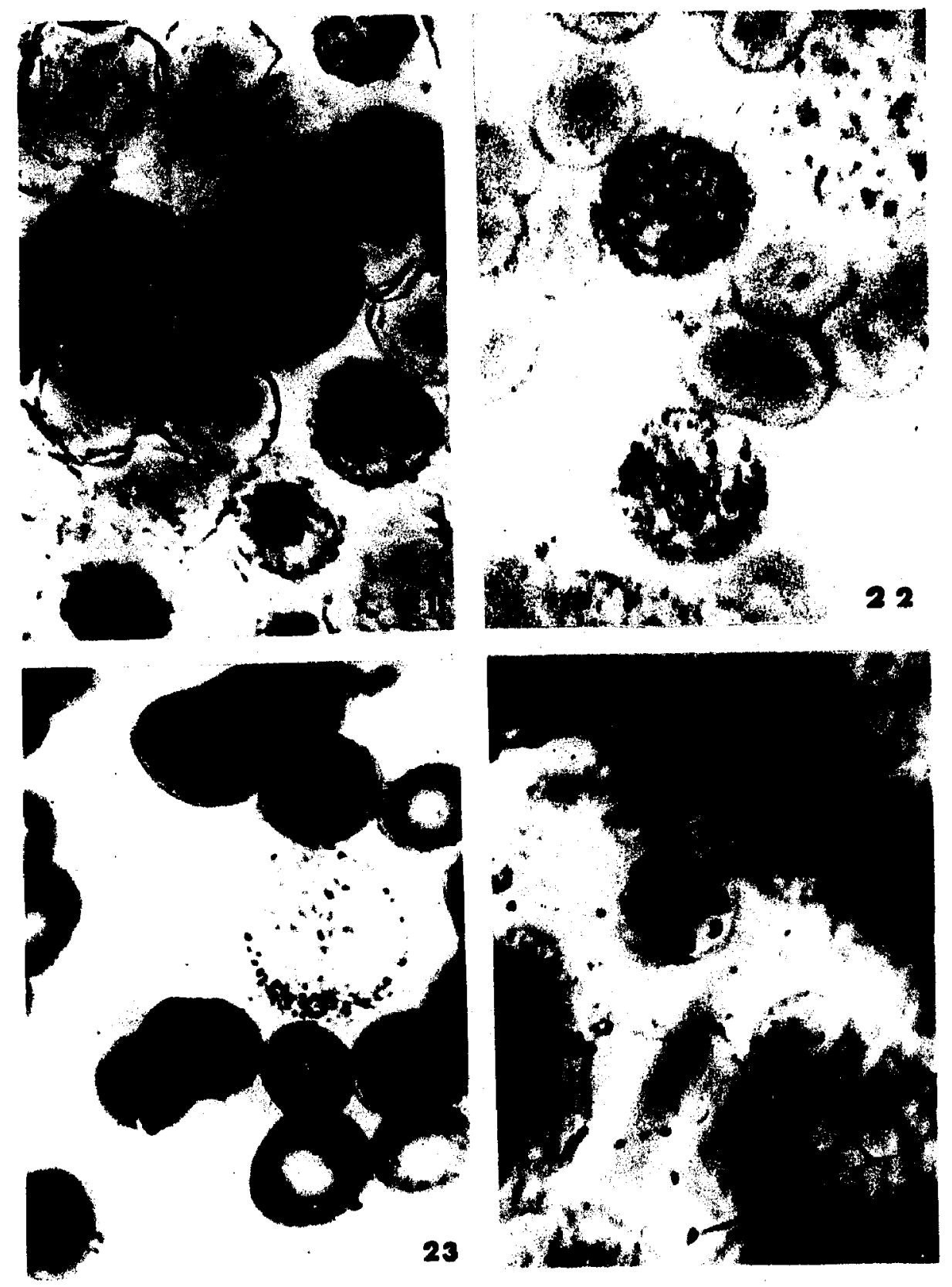

PLATE VI 
Legend for Plate VII.

Fig. 25.--Nonspecific esterase activity in a normal myeloblast showing a few fine granules scattered throughout the cell but most intense at the nuclear hof. X1600

Fig. 26.--Phosphorylase reaction in 1ymphoblasts of ALL showing fine and coarse granules and clumps of reactive material. The pattern is similar to the PAS reaction. $\mathrm{X} 1500$

Fig. 27.--Phosphorylase activity in monoblasts from AML showing the same coarse activity as was shown by the PAS reaction.

Fig. 28.--Phosphorylase activity in granulocytes from AGL. The myeloblast shows diffuse staining as with PAS. The phosphorylase activity increases with cellular maturation. X1600 

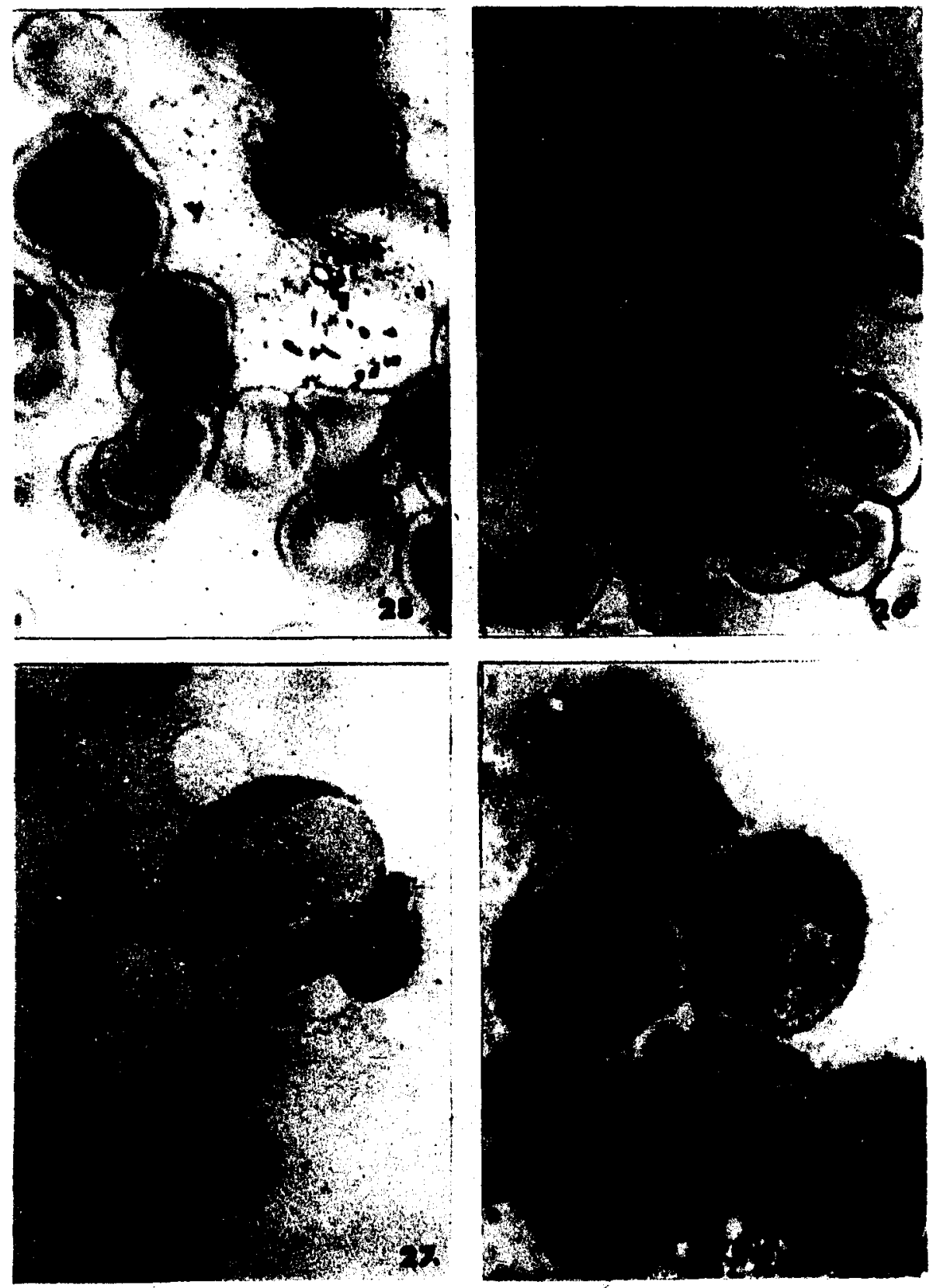

PIAIE VII 
Legend for Plate VIII.

Fig. 29.--Phosphorylase activity in a normal lymphocyte with moderately coarse granules depositing near the periphery of the cytoplasm. The pattern is similar to the PAS activity. X1500

Fig. 30.--Phosphorylase activity in a normal monocyte showing diffuse staining and a few coarse granules. X1500

Fig. 31.--Lactic dehydrogenase activity depositing as fine and coarse granules in lymphoblasts of ALL. X1500

Fig. 32.--Localization of lactic dehydrogenase activity in monoblasts of AML with most intense activity at the nuclear hof. X1500 

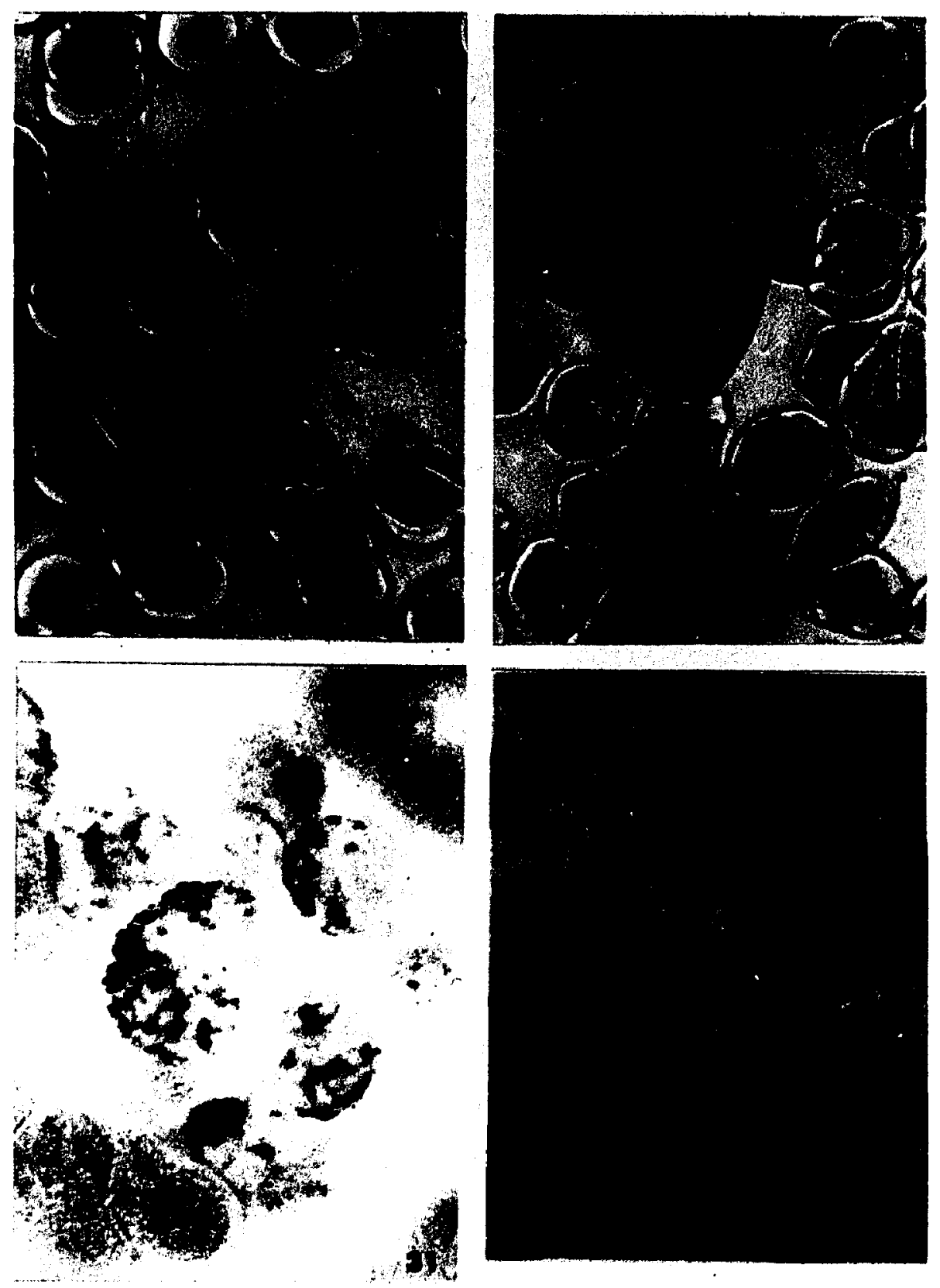

PLATE VIII 
Legend for Plate IX.

Fig. 33.--Intense perinuclear localization of lactic dehydrogenase in a myeloblast of AGL. X1500

Fig. 34.--Localization of lactic dehydrogenase activity as moderately coarse granules in a normal lymphocyte. X1500

Fig. 35.--Lactic dehydrogenase activity in a normal monocyte showing fine and coarse granules in a perinuclear position. X1500

Fig. 36.--Lactic dehydrogenase activity in a normal myeloblast showing a few moderately coarse granules near the periphery of the cytoplasm with most reactivity near the nuclear hof. X1200 

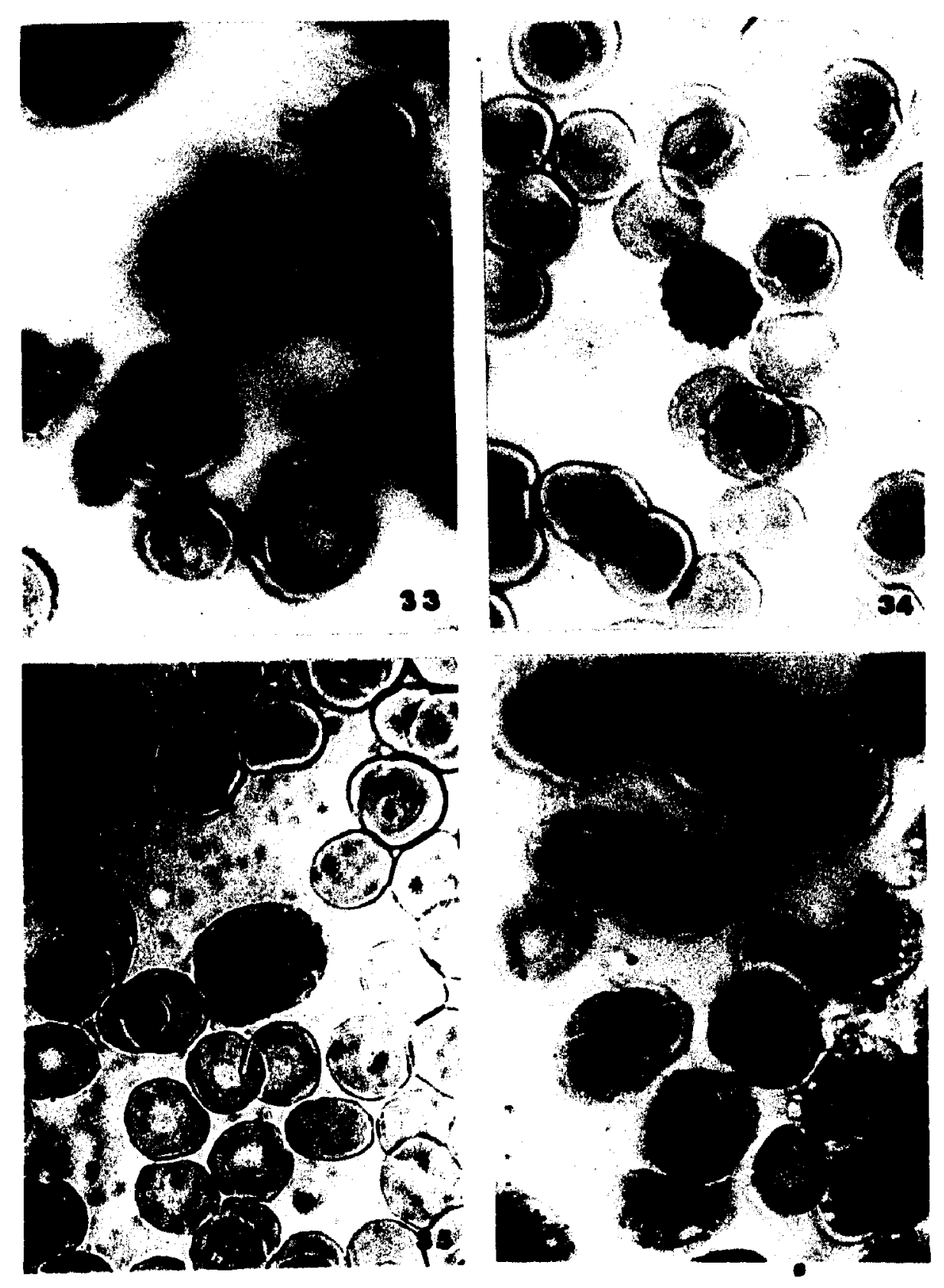

PLATE IX 
APPENDIX

WRIGHT'S STAIN

The technique used was that of Ackerman.

Reagents

(a) Wright's Stain:

Dissolve a capsule of Wright's dye in $60 \mathrm{~m} 1$ of fresh, anhydrous methyl alcohol. Shake. Add I tiny granule of Eosin $Y$.

Method

1. Place air dried films on a support (e.g., a cork).

2. Cover film completely with stain, and allow it to remain for $60-90$ seconds.

3. Dilute stain with distilled water. Add drop by drop, using approximately the same number of drops of water as of the dye. A greenish metallic scum should appear and the margins should show a reddish tint. Allow to remain 3-5 minutes.

4. Wash off with distilled water.

5. Mount in a synthetic mounting medium. 


\section{PERIODIC ACID-SCHIFF REACTION}

The technique used was that of Ackerman (1960).

\section{Reagents}

(a) Aqueous Periodic Acid:

Dissolve $500 \mathrm{mg}$ periodic acid crystals in $100 \mathrm{~m} 1$ distilled water. Store in a dark bottle.

(b) Schiff's Reagent (de Tomasi 1936):

Dissolve $1 \mathrm{~g}$ basic fuchsin in $200 \mathrm{~m} 1$ of boiling distilled water. Cool to exactly $50^{\circ} \mathrm{C}$ and filter. To the filtrate add $20 \mathrm{ml}$ of $1 \mathrm{~N}$ hydrochloric acid. Cool to $25^{\circ} \mathrm{C}$. Add $1 \mathrm{~g}$ potassium (or sodium) metabisulphite. Keep in the dark for 14-24 hours. Add $2 \mathrm{~g}$ activated charcoal. Shake for 1 minute and filter. Store the reagent in the dark at $0-4^{\circ} \mathrm{C}$. Allow to reach room temperature before use.

(c) Sulfurous Acid Rinse:

Prepare as follows:

$10 \%$ aqueous potassium metabisulphite . $.6 \mathrm{ml}$

$1 \mathrm{~N}$ hydrochloric acid . . . . . . .6 ml

Distilled water . . . . . . $110 \mathrm{~m} 1$ 
Method

1. Fix air dried films in formalin vapor for 5 minutes.

2. Rinse briefly in distilled water.

3. Place films in $0.5 \%$ aqueous periodic acid for 10 minutes.

4. Wash in distilled water.

5. Immerse in Schiff's reagent for 20 minutes.

6. Wash in 3 changes of sulfurous acid rinse, 2 minutes each.

7. Wash in running tap water 5-10 minutes.

8. Counterstain with $0.5-1 \%$ aqueous methy 1 green for 2 minutes. The methy1 green must be purified by repeated chloroform extraction.

9. Wash in running water.

10. Blot dry and mount with synthetic mounting medium.

\section{Results}

Intense red purple reaction indicates glycogen;

deep pink the presence of glycoprotein or mucopolysaccharides. 


\section{SUDAN BLACK B REACTION}

The technique used was that of Sheehan and Storey (1947).

\section{Reagents}

(a) Sudan Black B Solution:

Dissolve $0.3 \mathrm{~g}$ of Sudan black B powder in $100 \mathrm{ml}$ absolute ethanol.

(b) Buffer Solution:

Dissolve $16 \mathrm{~g}$ crystalline phenol in $30 \mathrm{ml}$ absolute ethanol. Add this to $100 \mathrm{ml}$ distilled water in which $0.3 \mathrm{~g}$ hydrated disodium hydrogen phosphate $\left(\mathrm{Na}_{2} \mathrm{HPO}_{4} \cdot 12 \mathrm{H}_{2} \mathrm{O}\right)$ has been dissolved.

(c) Working Stain Solution:

Add $40 \mathrm{ml}$ buffer solution to $60 \mathrm{ml}$ Sudan black B solution. Filter by suction. Store in cold. The stain, so prepared, can be used for 2-3 months.

Method

1. Fix air dried films in formalin vapor for 5-10 minutes.

2. Wash in running tap water for 10 minutes.

3. Immerse in working stain at room temperature for 1 hour. 
4. Wash with $70 \%$ ethanol for 2-3 minutes to remove excess dye.

5. Wash with tap water for 2 minutes.

6. Blot dry and counterstain with Leishman's stain.

7. Rinse in distilled water.

8. Mount in synthetic mounting medium.

\section{Results}

Sudanophilia can appear as faint localized reactivity to strong localized or heavy overall activity. 


\section{ACID PHOSPHATASE REACTION}

The technique used was that of Goldberg and Barka (1962). Reagents

(a) Formol-calcium:

Dissolve $1 \mathrm{~g}$ anhydrous calcium chloride in $60 \mathrm{~m} 1$ distilled water. Add $10 \mathrm{ml}$ formaldehyde and adjust to $\mathrm{pH}$ 7.0-7.2 with $1 \mathrm{~N}$ sodium hydroxide. Add distilled water to make $100 \mathrm{ml}$. Check $\mathrm{pH}$ of the fixative weekly and readjust if necessary. Store in refrigerator.

(b) Pararosanilin Solution:

Dissolve $1 \mathrm{~g}$ pararosanilin hydrochloride in $20 \mathrm{ml}$ distilled water and $5 \mathrm{ml}$ concentrated hydrochloric acid with gentle warming. Cool and filter. May be stored at room temperature.

(c) Sodium Nitrite Solution:

Dissolve $0.4 \mathrm{~g}$ sodium nitrite in $10 \mathrm{ml}$ of distilled water. Prepare fresh each day. 
(d) Michaelis Veronal Acetate Buffer Stock Solution $(0.15 \mathrm{M})$ :

Mix $9.714 \mathrm{~g}$ sodium acetate $\cdot 3 \mathrm{H}_{2} \mathrm{O}(5.85 \mathrm{~g}$ of anhydrous salt) and $14.714 \mathrm{~g}$ sodium barbital in carbon dioxide-free distilled water to a final volume of $500 \mathrm{ml}$.

(e) Stock Substrate Solution:

Dissolve $10 \mathrm{mg}$ naphthol AS-BI phosphate in $1 \mathrm{ml}$ $\mathrm{N}, \mathrm{N}$-dimethylformamide (DMF). If larger volumes for stock solutions are needed store in cold.

(f) Naphthol AS-BI Phosphate Hexazonium Pararosanilin Solution:

Mix $2.5 \mathrm{ml}$ Michaelis veronal acetate stock buffer solution with $0.5 \mathrm{ml}$ naphthol AS-BI phosphate stock solution and $6.0 \mathrm{ml}$ distilled water. Mix $0.4 \mathrm{ml}$ pararosanilin solution with $0.4 \mathrm{ml}$ sodium nitrite solution in a test tube. Add the pararosanilin-sodium nitrite solution to the substrate buffer mixer. Adjust this solution to $\mathrm{pH}$ 5 with IN sodium hydroxide. This solution should be freshly made prior to use. 
Method

1. Air dry blood films from 10-30 minutes at room temperature.

2. Fix in formol vapor for 1 minute followed by formo1-calcium for 3 minutes.

3. Rinse thoroughly in distilled water.

4. Place in freshly made naphthol AS-BI phosphate hexazonium pararosanilin solution for 2-3 hours at room temperature or $1-11 / 2$ hours at $37^{\circ} \mathrm{C}$.

5. Rinse thoroughly in distilled water.

6. Counterstain if desired with $1 \%$ methy 1 green in Michaelis veronal acetate buffer, $\mathrm{pH} 4$ for $30-60$ seconds.

7. Rinse in distilled water. Blot dry and mount with synthetic mounting medium.

$\underline{\text { Results }}$

Sites of acid phosphatase activity appear red. 


\section{ALKALINE PHOSPHATASE REACTION}

The technique used was that of Ackerman (1962). .

\section{Reagents}

(a) Dimethylformamide (DMF):

Purify the DMF by shaking with activated charcoal. Filter through Linde Molecular Sieve, type 4A, into a dry bottle containing more molecular sieve. Store in refrigerator.

(b) Substrate Stock Solution:

Dissolve $12.5 \mathrm{mg}$ of naphthol AS-MX phosphate in $5 \mathrm{~m} 1$ of purified dimethylformamide. Add $20 \mathrm{ml}$ distilled water and enough $1 \mathrm{M}$ sodium carbonate solution to adjust the substrate solution to $\mathrm{pH}$ 8. Add $130 \mathrm{ml}$ distilled water and $95 \mathrm{ml}$ of 0.2 M Tris buffer $\mathrm{pH}$ 8.3. The substrate solution should stand for at least 24 hours before use. It must be refrigerated and thoroughly mixed before use. 
(c) Incubation Solution:

Prior to use add $1 \mathrm{mg}$ Fast blue RR salt to each ml of substrate stock solution and filter. Magnesium or manganese ions may be added for activation.

(d) Formol-methanol:

Mix $10 \mathrm{ml}$ of formaldehyde in $90 \mathrm{ml}$ methanol.

Method

1. Fix films in cold formol-methanol for 30 seconds.

2. Wash in running tap water for 10 seconds.

3. Place in the incubating solution for 45 minutes at room temperature.

4. Wash in distilled water.

5. Counterstain with $1 \%$ aqueous neutra1 red for 30 seconds.

6. Wash in running distilled water.

7. Blot dry and mount in Kaiser's glycerine-jelly. $\underline{\text { Results }}$

Sites of alkaline phosphatase appear blue. Mature neutrophils, reticular, and reticulo-endothelial cells are only reactive cells in normal blood and bone marrow. 


\section{NONSPECIFIC ESTERASE REACTION}

The technique used was that of Wachstein and Wolf (1958).

\section{$\underline{\text { Reagents }}$}

(a) Substrate Solution:

$1 \%$ propylene glycol in $0.2 \mathrm{M}$

Phosphate buffer (pH 6.9).... . $40 \mathrm{ml}$

$1 \%$ naphthol AS acetate ..... $0.4 \mathrm{~m} 1$

Fast blue BB salt. . . . . . $80 \mathrm{mg}$

The substrate must be freshly prepared prior

to use.

\section{Method}

1. Fix air dried films in formalin vapor for 15 minutes.

2. Wash in distilled water.

3. Immerse in freshly prepared substrate at room temperature for 90 minutes.

4. Rinse in distilled water.

5. Counterstain for 10 minutes with $0.1 \%$ nuclear fast red in $5 \%$ aluminum sulphate solution.

6. Rinse in distilled water.

7. Mount in Kaiser's glycerine-jelly。 


\section{Results}

Sites of esterase activity appear blue with the deposition of dust-1ike and larger granular dye deposits in the cytoplasm. 


\section{PHOSPHORYLASE REACTION}

The technique used was slightly modified from that of Takeuchi and Kinoshita (1956) and Eränkö and Palkama (1961).

Reagents

(a) Substrate Solution:

Glucose-1-phosphate . . . . $150 \mathrm{mg}$ Adenosine-5-phosphate .... $10 \mathrm{mg}$ Glycogen . . . . . . . $10 \mathrm{mg}$ Sodium fluoride . . . . . . $180 \mathrm{mg}$ Polyviny1 pyrrolidone . . . . $900 \mathrm{mg}$ Insulin $40 \mathrm{i.u.} / \mathrm{ml}$..... $0.1 \mathrm{ml}$ Ethanol ........... $2 \mathrm{ml}$ Acetate buffer $0.1 \mathrm{M} \mathrm{pH} \mathrm{5.9} \mathrm{.} \mathrm{.} 10 \mathrm{ml}$ The solution must be freshly made and filtered.

(b) Gram's Iodine Solution:

Iodine .......... $1 \mathrm{~g}$ Potassium iodide....... . $2 \mathrm{~g}$ Sucrose solution $0.32 \mathrm{M}$. . . $300 \mathrm{ml}$

(c) Iodine-glycerine Mounting Medium:

Mix 1 part lodine solution with 5 parts of glycerine. 
Method

1. Allow air dried films to fix for 30 seconds in $70 \%$ acetone. B1ot dry.

2. Incubate in the substrate solution for $2-3$ hours at $37^{\circ} \mathrm{C}$.

3. Immerse in $40 \%$ ethanol for 2 minutes.

4. Allow to air dry.

5. Place in $0.32 \mathrm{M}$ sucrose for 5 minutes.

6. Place in Gram's iodine solution for 8 minutes.

7. Mount in iodine-glycerine.

\section{Results}

Phosphorylase activity appears dark-blue, violet-blue in color. The reaction closely parrallels the PAS reaction for glycogen and glycoprotein in both normal and abnormal blood and bone marrow cells. 


\section{LACTIC DEHYDROGENASE REACTION}

The technique used was modified from those described by Ackerman (1960), Quaglino and Hayhoe (1960), and Balogh and Cohen (1961). Polyvinyl pyrrolidone was used in the substrate as recommended by Scarpelli and Pearse (1958).

\section{Reagents}

(a) Sodium Azide Stock Solution:

Dissolve $0.065 \mathrm{~g}$ sodium azide crystals (M.W. 65.02) in $10 \mathrm{ml}$ distilled water. Makes a $0.1 \mathrm{M}$ stock solution.

(b) Sodium Lactate Stock Solution:

Dissolve $1.12 \mathrm{~g}$ sodium lactate crystals (M.W. 112.06) in $10 \mathrm{ml}$ distilled water. Makes a

1 M stock solution.

(c) Substrate Solution:

Phosphate buffer $0.2 \mathrm{M}, \mathrm{pH} 7.2$. $10 \mathrm{~m} 1$ Sodium lactate $0.2 \mathrm{M}$...... $10 \mathrm{ml}$ D.P.N. . . . . . . . $10 \mathrm{mg}$ Sodium azide $0.1 \mathrm{M}$...... $1.5 \mathrm{ml}$ P.V.P. . . . . . . . . $700 \mathrm{mg}$ 
Add $10 \mathrm{mg}$ Nitro B.T. dissolved in $10 \mathrm{~m} 1$ distilled water. Substrate solution may be -. kept in the freezer and thawed prior to use.

\section{Method}

1. Fix air dried films with $60 \%$ acetone for 30-60 seconds.

2. B1ot dry。

3. Incubate in substrate solution for 1-2 hours at $37^{\circ} \mathrm{C}$.

4. Rinse in distilled water.

5. Counterstain with $1 \%$ aqueous neutra1 red for 30 seconds.

6. Blot dry and mount in Kaiser's glycerine-jelly.

\section{$\underline{\text { Results }}$}

Sites of lactic dehydrogenase activity appear

blue-purple. 


\section{BIBLIOGRAPHY}

1. Ackerman, G. A.: A modification of the Sudan black B technique for the possible cytochemical demonstration of masked lipids. Science 115:629, 1952.

2. Ackerman, G. A.: Histochemistry of normal and leukemic 1ymphocytes. J. Histochem. Cytochem. $7: 318,1959$.

3. Ackerman, G. A.: Cytochemistry of the Iymphocytes: Phase microscope studies. In: The Lymphocyte and Lymphocytic Tissue. Internat. Acad. Pathol. Monograph. J. W. Rebuck, ed. New York, Paul B. Hoeber, Inc., 1960, pp. 28-53.

4. Ackerman, G. A.: Histochemical demonstration of dehydrogenase activity in the cells of normal human blood and bone marrow. J. Biophys. Biochem. Cytol. $8: 61,1960$ 
5. Ackerman, G. A.: Histochemical demonstration of indoxyl acetate esterase activity in normal human blood and bone marrow. Lab. Invest. 9:298, 1960.

6. Ackerman, G. A.: Histochemical demonstration of aminopeptidase activity in the leukocytes of blood and bone marrow in man. J. Histochem. Cytochem. $8: 386,1960$.

7. Ackerman, G. A.: Substituted naphthol AS phosphate derivitives for the localization of leukocyte alkaline phosphatase activity. Lab. Invest. $11: 563,1962$.

8. Ackerman, G. A.: Electron microscopy of the bursa of Fabricius of the embryonic chick with particular reference to the lympho-epithelial nodules. J. Cel1 Biol. : 13:127, 1962 .

9. Ackerman, G. A.: Histochemical demonstration of aminopeptidase activity in the cells of the blood and bone marrow from various hematological disorders. Nature 197:189, 1963. 
10. Ackerman, G. A.: Histochemical differentiation during neutrophil development and maturation. Ann. N. Y. Acad. Sci. 113:537, 1964.

11. Ackerman, G. A., and Bellios, N. C.: A study of the morphology of the living cells of blood and bone marrow in vital films with the phase contrast microscope. I. Normal blood and bone marrow. Blood 10:3, 1955.

12. Ackerman, G.A., and Bellios, N. C.: A study of the morphology of the living cells of blood and bone marrow in supravital films with the phase contrast microscope. II. Blood and bone marrow from various hematologic dyscrasias. Blood 10:1183, 1955.

13. Ackerman, G. A., Knouff, R. A., and Hoster, H.A.: Cytochemistry and morphology of neoplastic and nonneoplastic human lymph node cells with special reference to Hodgkin's Disease. J. Nat. Cancer Inst. $12: 465,1951$. 
14. Ammon, R., and Jaarma, J.: Enzymes hydrolyzing fats and esters. In: The Enzymes. Chemistry and Mechanism of Action. J. B. Sumner and K. Myrbäck, ed. New York, Academic Press, Inc., 1950, vo1. 1, p. 390 .

15. Antoniolo, J. A., Baer, A., and Vannotti, A.: Les phosphátases leucocytaires alcaline et acide: Variations pathologiques, régulation humorale et rapports avec les phosphatases plasmatiques. Acta Haemato1. 34:129, 1965.

16. Astaldi, G., and Verga, L.: The glycogen content of the cells of lymphatic leukaemia. Acta Haematol. $17: 129,1957$.

17. Bainton, D. F., and Farquhar, M. G.: Enzyme composition of polymorphonuclear leukocyte granules. J. Ce11 Biol. $31: 8 \mathrm{~A}, 1966$.

18. Bakalos, D.: The significance of the non-specific esterase activity and the sudanophilia of the monocytes. Europ.Soc. Haemato1. Proc. 9:125, 1963. 
19. Ballif, R. N., and Kimbrough, C.: Studies on leucocyte granules after staining with Sudan black B and May-Grunwald Giemsa. J. Lab. C1in. Med. $32: 155,1947$.

20. Balogh, K., and Cohen, R. B.: Histochemical demonstration of diaphorases and dehydrogenases in normal human leukocytes and platelets. Blood $17: 491,1961$

21. Barka, T.: A simple azo-dye method for the histochemical demonstration of acid phosphatase. Nature $187: 248,1960$.

22. Barka, T.: Cellular localization of acid phosphatase activity. J. Histochem. Cytochem. $10: 231,1962$.

23. Barka, T., and Anderson, P. J.: Histochemical methods for acid phosphatase using hexazonium pararosanilin as coupler. J. Histochem. Cytochem . $10: 741,1962$.

24. Barka, T., and Anderson, P. J.: Histochemistry॰ Theory, Practice, and Bibliography. New York, Harper and Row, Inc., 1963. 
25. Barka, T., and Ornstein, L.: Some observations on the reaction of Schiff reagent with aldehydes. J. Histochem. Cytochem. $8: 208,1960$.

26. Barrnett, R. J.: The histochemical distribution of protein-bound sulfhydryl groups. J. Nat. Cancer Inst. $13: 905,1953$.

27. Barron, E. S. G.: The importance of sulfhydryl groups in biology and medicine. Texas Rep. Biol. and Med. 11:653, 1953.

28. Beck, W. S.: The control of leukocyte glycolysis. J. Biol. Chem. 232:251, 1958 。

29. Beck, W. S.: Occurrence and control of the phosphogluconate oxidation pathway in normal and leukemic leukocytes. J. Biol. Chem。232:271, 1958 .

30. Beck, W. S., and Valentine, W. N.: Biochemical studies on leukocytes. II. Phosphatase activity in chronic 1ymphocytic leukemia, acute leukemia, and miscellaneous hematologic conditions. J. Lab. C1in. Med. 38:245, 1951 . 
31. Beck, W. S., and Valentine, W. N.: The aerobic carbohydrate metabolism of leukocytes in health and leukemia. II. The effect of various substrates and coenzymes on glycolysis and respiration. Cancer Res. 12:823, 1952 .

32. Bloom, M. L., and Wislocki, G. B.: Localization of lipids in human blood and bone marrow cells. Blood 5:79, 1950.

33. Boivin, $P_{\circ}$, and Robineaux, R.: Histochimie des cellules sanquines. II. Phosphatase alcaline. Le Sang 27:535, 1956.

34. Bottomly, R. H., Locke, S. J., and Ingram, H. C.: Lactic dehydrogenase of human chronic 1ymphocytic leukemic leukocytes. Blood 27:85, 1966 。

35. Braunstein, H.: Esterase in leukocytes. J. Histochem. Cytochem. 7:202, 1959.

36. Brausil, B.: Diagnostic differences between atypical myeloblasts and lymphoblasts in the phase contrast microscope. Acta Haematol. $12: 276,1954$. 
37. Broadbridge, C.: The use of special stains in the diagnosis of the acute leukemias. Canadian J. Med. Technol。27:39, 1965 .

38. Bruhn, H. D.: The use of the periodic acid-Schiff reaction in the diagnosis of immature cell monocytic leukemia. Blut 11:306, 1965.

39. Burstone, M. S.: The relationship between fixation and techniques for the histochemical localization of hydrolytic enzymes. J. Histochem. Cytochem. $6: 322,1958$.

40. Burstone, M. S.: Histochemica1 demonstration of phosphatases in frozen sections with Naphthol AS phosphates. J. Histochem. Cytochem. 9:146, 1961.

41. Burstone, M. S.: Enzyme Histochemistry. New York, Academic Press, 1962.

42. Burton, J. F.: Histochemical demonstration of acid phosphatase by an improved azo-dye method. J. Histochem. Cytochem. $2: 88,1954$.

43. Campanacci, L., Pieragali, E., and Stura, S.: Sulfhydry1 groups in the bone marrow and blood of leukemic subjects. Giorn. Clin. Med. (Parma) $36: 572,1955$. 
44. Cohn, R. D., Kaplan, N. 0., Levine, L., and Zwilling, E.: Nature and development of lactic dehydrogenases. Science 136:962, 1962 .

45. Dahlquist, A., 01sson, I., and Norden, A.: The periodate-Schiff reaction: Specificity, kinetics, and reaction products with pure substrates. J. Histochem. Cytochem. 13:423, 1965.

46. Dameshek, W., and Gunz, F.: Leukemia. New York, Grune and Stratton, Inc., 1964.

47. Darmady, E. M., and Davenport, S. G. T.: Haematologica1 Technique. New York, Grune and Stratton, Inc., 1963.

48. Davenport, H. A.: Histological and Histochemical Technics. Philadelphia, W. B. Saunders Co., 1960.

49. de Duve, C.: The lysosome concept. In: Lysosomes. A. V. S. de Reuck and M. P. Cameron, ed. London, J. and A. Churchil1, Ltd., 1963, pp. 1-30.

50. Defendi, V.: Observations on naphthol staining and the histochemical localization of enzymes by naphtho1-azo dye technique. J. Histochem. Cytochem. $5: 1,1957$. 
51. Delellis, R., and Fishman, W. H.: The variable of $\mathrm{pH}$ in the bromindoxyl acetate method for the demonstration of esterase. Blood 13:297, 1965.

52. De Souza, E. J., and Kothare, S. N.: A method for the cytochemical demonstration of succinic dehydrogenase in human leukocytes. J. Histochem. Cytochem。 7:77, 1959 .

53. Dioguardi, N., Agostoni, A., and Fiorel1i, G.: Characteristics of lactic dehydrogenase in cells of myeloid leukemia. Enzymol. Biol, et Clin. $2: 116,1962$.

54. Dioguardi, N., Agostoni, A., and Schweizer, M.: Multiple molecular forms of lactic dehydrogenase of normal and leukemic human lymphocytes. Enzymol. Biol. C1in. 5:3, 1965.

55. Dobreva-Marinova, A., and Bojadjieva-Michailova, A.: Comparative cytochemical and electron microscopic investigations of human acute leukemia. A. Ges. Inn. Med. 19:216, 1964 . 
56. Dobrogorski, O. J., and Braunstein, H.: Histochemical study of staining lipid, glucogen, and mucin in human neoplasms. Am. J. C1in. Path. $40: 435,1963$.

57. Downes, H. R.: The Chemistry of Living Cells. New York, Harper and Row, Inc ,, 1962.

58. Eräkkö, O., and Palkama, A.: Improved localization of phosphorylase by the use of polyvinyl pyrrolidine and high substrate concentration. J. Histochem. Cytochem. 9:585, 1961 .

59. Evans, G. W., Whinney, C. L., and Tsou, K. C.: A new histochemical method for acid phosphatase by the use of 5-iodoindoxyl phosphate. J. Histochem. Cytochem. 14:171, 1966.

60. Fine, I. H., Kaplan, N. O., and Kuftinec, D.:

Developmental changes of mammalian lactic dehydrogenases. Biochemistry 2:116, 1962 .

61. Fondy, T. P., and Kaplan, N. 0.: Structural and functional properties of the $H$ and $M$ subunits of lactic dehydrogenase. Ann. N. Y. Acad. Sci. $119: 888,1965$. 
62. Freschi, A., Bianchini, E., Cambiaggi, G., Sacchetti, C., and Salvidio, E.: Studies on the biological behavior of the cells of acute leukaemia. Acta Haemato1. $16: 126,1956$.

63. Gahrton, E.: Microspectrophotometric quantitation of the periodic acid-Schiff reaction in human neutrophil leukocytes based on a model system of glycogen microdroplets. Exper. Cell Res. 34:488, 1964.

64. Gavosto, F., Maraini, G., and Pileri, A.: Nucleic acids and protein metabolism in leukemia. Blood $16: 1555,1960$.

65. Gavosto, F., Pileri, A., Bachi, C., and Pegararo, L.: Proliferation and maturation defect in acute leukemic cells. Nature 203:92, 1964.

66. Gibb, R. P., and Stowe11, R. E.: Glycogen in human blood cells. Blood 4:569, 1949 .

67. Glick, D.: Quantitative Chemical Techniques of Histo- and Cytochemistry. New York, John Wiley and Sons, 1963。 
68. Goldberg, A. F.: Acid phosphatase in leukocytes of normals, patients with toxi-infectious states, and infectious mononucleosis, eosinophilias, and Auer bodies. Fed. Proc. 21:74, 1962。

69. Goldberg, A. F.: Acid phosphatase activity in Auer bodies. Blood 24:305, 1964.

70. Goldberg, A. F., and Barka, T.: Acid phosphatase activity in human blood cells. Nature 195:297, 1962.

71. Goldfischer, S., Essner, E., and Novikoff, A. B.: The localization of phosphatase activities at the level of ultrastructure. B1ood 12:72, 1964 .

72. Goldman, R. D., and Kaplan, N. 0.: Alterations of lactic dehydrogenase in human neoplasms. Biochem. Biophys. Acta $77: 515,1963$.

73. Gomori, G.: The periodic acid-Schiff stain. Am. J. Clin. Path. 22:277, 1952 .

74. Gomori, G.: Chloracyl esters as histochemical substrates. J. Histochem. Cytochem. 1:469, 1953. 
75. Grignoni, F., Colonna, A., Marte11i, M., and Tonato, M.: Energy metabolism of leukocytes. Consumption of oxygen by normal and leukemic leukocytes. Haematol. Arch. 49:767, 1964.

76. Grigani, F., and Burnetti, P.: Some aspects of the energetic metabolism of normal and leukemic leukocytes. Sangre 9:144, 1964.

77. Guha, $S_{0}$, and Wegmann, $R_{0}$ : Histoautoradiographic localization of phosphorylase activity. J. Histochem. Cytochem. 13:148, 1965.

78. Guha, S., Wedmann, R.: The use of c14-1abelled substrate in histochemical demonstration of different forms of phosphorylase. Histochemie 6:350, 1966 .

79. Haight, W. F., and Rossiter, R. J.: Acid and alkaline phosphatase in white cells. Data for the 1ymphocyte and the polymorphonuclear leukocyte of man and the rabbit. Blood 5:267, 1950 .

80. Hardin, E. B.; Valentine, W. N., Tollette, J. H., and Lawrence, J. S.: Esterase and lipase activity of leucocytes and erythrocytes in health and disease. Am. J. Med。Sci。 $229: 397,1955 . \quad$. 
81. Hardonk, M. J., and Van Duijn, P.: The mechanism of the Schiff reaction as studied with histochemical model systems. J. Histochem. Cytochem. 12:748, 1964 .

82. Harper, H. A.: Review of Physiological Chemistry. Los Altos, Lange Medical Publications, 1963.

83. Hayhoe, F. G. J.: Leukaemia. Research and Clinical Practice. Boston, Little Brown \& Co., 1960, pp. 73-96.

84. Hayhoe, F. G. J.: Current Research in Leukaemia. Cambridge, Cambridge University Press, 1965, pp. 1-15, 124-137, 178-235.

85. Hayhoe, F. G. J., and Quaglino, D.: Cytochemical demonstration and measurement of leucocyte alkaline phosphatase activity in normal and pathological states by a modified azo-dye coupling technique. Brit. J. Haemato1. 4:375, 1958 .

86. Hayhoe, F. G. J., Quaglino, D., and Flemans, R. J.: Consecutive use of Romanowsky and periodic acidSchiff techniques in the study of blood and bone marrow cells. Brit. J. Haemato1. 6:23, 1960. 
87. Hayhoe, F. G. J., Quaglino, D., and Do11, R.: The Cytology and Cytochemistry of Acute Leukemias. London, F. Mildner \& Sons, 1964.

88. Hedeskov, C. J., and Esmann, V.: Respiration and glycolysis of normal human lymphocytes. Blood $28: 163,1966$.

89. Hert1, M.: Morphologische und zytochemische Untersuchungen an Zellen der akuten Leukose. Folia Haemato1. Neue Folge 3:296, 1959.

90. Hert1, M.: Cytochemical characteristics of cells in acute leukemia. Fortschr. Med. 83:959, 1965.

91. Hirsch, J. G., and Cohn, A. Z.: Digestive and autolytic functions of lysosomes in phagocytic cells. Fed. Proc. $23: 1023,1964$.

92. Hoffman, E. C., and Lucich, V. J.: The clinical application of a modified azo-dye technique for the determination of alkaline phosphatase activity in neutrophils. Cleveland Clin. Quat. 27:146, 1960.

93. Holt, S.: J., and Hicks, R. M.: Studies on formalin fixation for electron microscopy and cytochemical staining purposes. J. Biophys. Biochem. Cytol. $11: 31,1961$. 
94. Hooghwinke1, G. J. M., and Smits, G.: The specificity of the periodic acid-Schiff reaction technique studied by a quantitative test-tube method. J. Histochem. Cytochem. 5:120, 1957.

95. Hori, S. H.: Effect of EDTA on histochemical demonstration of phosphorylase activity. J. Histochem. Cytochem. 14:501, 1966.

96. Hugan, J., and Borgers, M.: A direct method for the electron microscopic visualization of alkaline phosphatase activity. J. Histochem. Cytochem. $14: 429,1966$.

97. Itoga, T., and Oki, K.: Studies on the PAS reaction of 1ymphocytes and abnormal cells in the various lymphogenic malignant neoplasma. Kyushu Hemato1. Soc. J. $14: 163,1964$.

98. Jeffree, G. M., and Taylor, K. B.: Preparation of naphthol AS-TR phosphate for localization of phosphatase. J. Histochem. Cytochem. 9:93, 1961.

99. Jervis, H., and Labrec, E. H.: Correlation of acid phosphatase activity with degree of bacterial infection in Hela cells. J. Histochem. Cytochem. $14: 196,1966$. 
100. Kabelitz, H. J.: The monocytic hemoblastoses. Täg. Praxis 6:203, 1965.

101. Kahn, P.: Cytochemical investigations in acute leukemias. K1in. Wochschr. 43:1038, 1965.

102. Kaplow, L. S.: A histochemical procedure for localizing and evaluating leukocyte alkaline phosphatase activity in smears of blood and bone marrow. Blood 10:1023, 1955.

103. Kaplow, L. S., and Burstone, M. S.: Cytochemical demonstration of acid phosphatase on hematopoietic cells in health and in various hematological disorders using azo-dye techniques. J. Histochem. Cytochem. 12:805, 1964 .

104. Kasten, F. H.: The chemistry of Schiff's reagent. Internat. Rev. Cytol. $10: 1,1960$.

105. Kawano, M.: Enzymic properties of chicken leukemic tumor. I. Glycolysis of cancer cells. Okayama Igak. Zasshi 76:299, 1964 .

106. Keane, C. T.: The diagnostic value of leukocyte stains in leukemia. Postgrad. Med. J. 41:753, 1965. 
107. Keller, M., and Tanka, D.: Preservation of the iodine glycogen complex of the phosphorylase reaction. Acta Histochemica 22:73, 1965.

108. Kerppola, W.: Observations on phosphatase content of blood and bone marrow cells in normal and pathologic hemopoiesis. Blood 6:454, 1951.

109. Killmann, S. A., Cronkite, E. P., Robertson, J. S., Fliedner, T. M., and Bond, V. P.: Estimation of the phases of the life cycle of leukemic cells from labelling in human beings with tritiated thymidine. Lab. Invest. 12:671, 1963.

110. Koenig, H.: Intravital staining of lysosomes by basic dyes and metallic ions. J. Histochem. Cytochem. $11: 120,1963$.

111. Koler, R. D., Seaman, A. J., Osgood, E. E., and Van Bellingham, P.: Myeloproliferative Diseases. Diagnostic value of the leukocyte alkaline phosphatase test. Am. J. C1in. Path. 30:295, 1958.

112. Komma, D. J.: Characteristics of the esterases in human cells grown in vitro. J. Histochem. Cytochem. 11:619, 1963 . 
113. Kovaleva, L. G.: Activity changes of alkaline phosphatase and nucleic acids during acute 1eukemia. Problemy Gemato1. Pereli. Krovi $10: 20,1965$ 。

114. Kugler, J. H., and Wilkinson, W. J. C.: Glycogen fractions and their role in the histochemical detection of glycogen. J. Histochem. Cytochem. $8: 195,1960$.

115. Lajtha, L. G.: Bone marrow cell metabolism. Physiol. Rev. $37: 50,1957$ 。

116. Lajtha, L. G.: Problems of bone marrow cell kinetics. Postgrad. Med. J. 38:41, 1962 .

117. Larner, J.: The action of branching enzymes on outer chains of glycogen. J. Bio1. Chem. 202:491, 1953.

118. Latner, A. L., and Skilien, A. W.: Lactate dehydrogenase isoenzymes in foeta1 and neonatal tissues. J. Embryo1. Exp. Morph. 12:501, 1964. 119. Lillie, R. D., and Burtner, H. J.: Stable sudanophilia of human neutrophil leucocytes in relation to peroxidase and oxidase. J. Histochem. Cytochem. $1: 8,1953$. 
120. Löffler, H.: Untersuchungen über die Aktivität der alkalischen Phosphatase und der unspezifisiehen Esterase in dem Retikulumze1len der Knockenmarkes. Ein Vergleich zwischen Knockenmark und Lymphknoten. Folia Haematol. Neue Folge 6:164, 1961.

121. Löffler, H.: Zur Differenzierung unreifzelliger Leukosen mit cytochemischen Methoden. Folia Haemato1. 8:112, 1963.

122. Löffler, H., and Berghuff, W.: A method for the detection of acid phosphatase in smears. Klin. Wochschr. 40:363, 1962.

123. Löffler, H., and Schubert, J. C. F.: Zum histochemischen Nachweis der Esterasen in Zellen des Blutes. Klin. Wochschr. $37: 563,1959$.

124. Lorenzi, T. F.: Cytochemistry of blood cells as a means of evaluating the development of leukemic states. J. Braseleiro Med. 9:1227, 1965.

125. Maggi, V., Franks, L. M., and Carbone11, A. W.: Histochemical study of a number of hydrolases including a new acid phosphatase in various tissues of men and mice. Histochemie 6:305, 1966. 
126. Maldonado, J. E., and Hanlon, D. G.: Monocytosis: A current appraisa1. Mayo C1inic Proc. 40:248, 1965.

127. Markert, C. L.: Lactate dehydrogenase isozymes: Dissociation and recombination of subunits. Science 140:1329, 1963.

128. Mathur, B. B. L., and Vanikar, S. V.: Alkaline phosphatase activity in health and disease. Lab. Invest. $14: 565,1965$.

129. Mauer, A. M., and Fisher, V.: In vivo studies of ce11 kinetics in acute 1eukemia. Nature 197:574, 1963.

130. Meislin, A. G., Lee, S. L., and Wasserman, L. R.: Leukocyte alkaline phosphatase activity in hematopoietic disorders. Cancer 12:760, 1959.

131. Meldolesi, J.: Histochemical study of some dehydrogenases of nucleated cells of peripheral and bone marrow blood of both normal persons and patients with blood diseases. Haemato1. Arch. $49: 644,1964$. 
132. Merker, H.: Alkaline phosphatase of leukocytes. Its hematological and clinical significance. Deutsche Med. Wochschr. 90:484, 1965.

133. Merker, H., and Heilmeyer, L.: Die alkalische Phosphatase neutrophiler Leukozyten. Deutsche Med. Wochschr. 85:253, 1960 .

134. Meyers, M., Hines, D. R., and Bishop, R. C.: Acute leukemia in adolescents and adults. Ann. Intern. Med. $63: 411,1965$ 。

135. Micu, D., and Mihailescu, E.: The value of the determination of some leukocyte phosphatases in various malignant diseases of the blood. Folia Haemato1. 84:329, 1965.

136. Miller, F.: Electron microscopic cytochemistry of leucocyte granules. Electron Microscopy. Tokyo, Maruzen Co., Ltd., 1966, II, pp. 71-72。

137. Mitus, W. J., Bergna, I. J., Mednicoff, J. B., and Dameshek, $W_{.}:$Atypical myeloblasts in acute leukemia. Clin. Res. Proc. 5:149, 1957. 
138. Mitus, W. J., Bergna, L. J., Mednicoff, J. B., and Dameshek, W.: Cytochemical studies of glycogen content of lymphocytes in lymphocytic proliferations. Blood 13:748, 1958。

139. Mitus, W. J., Bergna, L. J., Mednicoff, J. B., and Dameshek, W.: Alkaline phosphatase of mature neutrophils in chronic forms of the myeloproliferative syndrome. Am. J. Clin. Path. 30:285, 1958.

140. Mizutoni, A., and Barrnett, R. J.: Fine strúctural localization of phosphatase activity at $\mathrm{pH} 9$. Nature 206:1001, 1965 .

141. Moloney, W. C., Fliegelman, L., and McPhearson, K.: The use of naphthol AS-D chloroacetate as a substrate for the study of leucocyte esterase activity. J. Histochem. Cytochem. 7:306, 1959 .

142. Monis, B., and Rutenburg, A. M.: Alkaline phosphatase in leucocytes by an azo-dye method. Stain Techn. 34:339, 1959. 
143. Nachlas, M. A., Goldstein, R. P., Rosenblatt, D. H., Kitsch, M., and Seligman, A. M.: Influence of chemical structure on the rate of azo coupling and its significance in histochemical methodology. J. Histochem. Cytochem. 7:50, 1959.

144. Nachlas, M. M., and Seligman, A. M.: Evidence for the specificity of esterase and lipase by the use of three chromogenic substrates. J. Biol. Chem. $181: 343,1949$.

145. Nicolau, C. T., Nicoara, S., Popescu, E., Faigur, S, , Butoianu, E., Ursea, C., and Popescu-Mut, I.: Cytochemical studies in 41 cases of acute leukemia. Med. Interna 17:515, 1965.

146. Novikoff, A. B.: Distinguishing substrate-specific phosphatases. J. Histochem. Cytochem. 6:251, 1958 . 147. Novikoff, A. B., and Masek, B.: Survival of lactic dehydrogenase and DPHN-diaphorase activities after formol-calcium fixation. J. Histochem. Cytochem. $6: 217,1958$.

148. Novikoff, A. B., Essner, E., and Quintana, N.: Golgi apparatus and lysosomes. Fed. Proc. $23: 1010,1964$. 
149. Nowe11, P. C.: Differentiation of human leukemic leukocytes in tissue culture. Exp. Cell Res. $19: 267,1960$.

150. Ogawa, K., Mizuno, N., and Okamoto, M.: Lysosomes in cultured cells. J. Histochem. Cytochem. $9: 202,1961$.

151. Ogawa, K., and Shinonaga, Y.: Intramitochondrial localization of oxidative enzymes in cultured cells. J. Histochem. Cytochem. 10:104, 1962 .

152. Osgood, E. E.: A unifying concept of the aetiology of the leukaemias, 1ymphomas, and cancers. J. Nat. Cancer Inst. $18: 155,1957$.

153. Pearse, A. G. E.: Histochemistry. Theoretical and Applied. Boston, Little Brown \& Co., 1960.

154. Perillie, P. E., and Finch, S. C.: Alkaline phosphatase activity of exudative leukocytes in acute leukemia. Blood 18:572, 1961.

155. Perugini, S.: Sul significato del1' affinità dei granuli neutrofili dei leucociti per $i$ coloranti tipo Sudan. Experientia 10:381, 1954. 
156. Pfleiderer, G., and Wachsmuth, E. D.: Alters-und . Funktionsabhängigi Differenzierung der Lactatdehydrogenase menschlicher Organe. Biochem. Z. $334: 185,1961$.

157. Pittman, G. R., and Senhauser, D. A.: Acute promyelocytic leukemia. A clinicopathologic study of three cases. Lab. Invest. 14:590, 1965.

158. Plagemann, P. G., Gregory, K. F., and Wroblewski, F.: The electrophoretically distinct forms -of mammalian lactic dehydrogenase. J. Biol. Chem. $235: 2282,1960$.

159. Plenert, W.: Methodische Studien zur Zytochemie der Leukozytenphosphatasen. III Mitt. Der Gebrauch verschiedener Substrate im Sauren und neutralen Milieu. Histochemie 1:268, 1959.

160. Plum, C. M.: Die alkalische Phosphatase an den Zellen des normalen und pathologischen Knockenmarkes und des peripheren Blutes. Acta Haemat. 4:73, 1950.

161. Quaglino, D., and Hayhoe, F. G. J.: Observations on the periodic acid-Schiff reaction in lymphoproliferative diseases. J. Path. Bact. 78:521, 1959. 
162. Quaglino, D., and Hayhoe, F. G. J.: Acetone fixation for the cytochemical demonstration of dehydrogenases in blood and bone-marrow cells. Nature $187: 85,1960$.

163. Quaglino, D., and Hayhoe, F. G. J.: Phosphorylase activity in haemic cells. Nature 194:929, 1962.

164. Rabinovitch, M., and Andrencci, D.: Histochemical study of acid and alkaline phosphatase distribution in normal human bone marrow smears. Blood 4:580, 1949.

165. Reve1, J. P.: Electron microscopy of glycogen. J. Histochem. Cytochem。12:104, 1964 。

166. Rogister, G., and Gerebtzoff, M. A.: Recherches histochemiques sur les acetylcholine et choline esterases. V. Localization dons les éléments figures du song et dans les organes hémopoiétiques. Acta Anat. 32:39, 1958 .

167. Rosales, C. L., Bennett, J. M., and Rutenburg, A. M.: An azo-dye method for the histochemical demonstration of leucocyte acid phosphatase. J. Histochem. Cytochem. 13:698, 1965 . 
168. Rudolph, V. G., and Schmitz, G.: Zytochemische Nachweismethoden Dehydrogenases in menschlichen Thrombozyten. Folia Haematol. Neue. Folge. $6: 379,1962$.

169. Rutenberg, A. M., Barrnett, R. J., Tsou, K. C.,

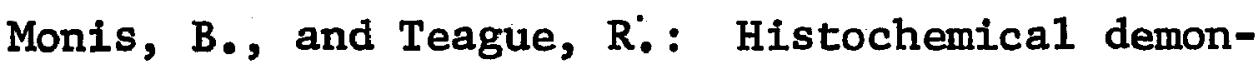
stration of alkaline phosphatase activity by a simultaneous coupling technique using naphthol AS phosphate. J. Histochem. Cytochem. 6:90, 1958 .

170. Sabatini, D., Bensch, K., and Barrnett, R. J.: Cytochemistry and electron microscopy. The preservation of cellular ultrastructure and enzymatic activity by aldehyde fixation. J. Cell Biol. $17: 19,1963$.

171. Sanada, H., Ota, A., Kotsuka, T., Onoye, O., Sakikawa, Y., Saihara, T., and Honke, K.: Cytological classification of the leukemias. Okayama Igakkai Zasshi 76:689, 1964 . 
172. Scarpe11i, D. G., Hess, R., and Pearse, A. G. E.: The cytochemical localization of oxidative enzymes. I. Diphosphopyridine nucleotide diaphorase and triphosphopyridene nucleotide diaphorose. J. Biophys. Biochem. Cyto1. 4:747, 1958 .

173. Scarpe11i, D. G., and Pearse, A. G. E.: Physical and chemical protection of cell constituents and the precise localization of enzymes. J. Histochem. Cytochem。6:369, 1958 .

174. Setala, K.: Defective cell maturation; an alternative to accelerated cell division as target for cancer therapy. Progr. Exp. Tumor Res. $5: 1,1964$.

175. Sheehan, H. L., and Storey, G. W.: An improved method of staining leucocyte granules with Sudan black B. J. Pathol. Bacteriol. 59:336, 1947. 176. Sirola, I., and Sirola, K.: A histochemical study of alkaline phosphatase in the leukocytes of blood and bone marrow in various diseases. Acta. Haemato1. $18: 313,1957$ 。 
177. Starkweather, W. H., Spencer, H. H., and Schoch, H. K.: The lactate dehydrogenases of hemopoietic cells. Blood 28:860, 1966.

178. Stave, U.: Über Enzyme der Glykolyse in Leukozyten von Kindern. Enzymo1. Bio1. C1in. 1:34, 1961.

179. Storti, E., and Perugini, S.: Cytochemical researches on the lipids of the hematic cells with particular attention to those of acute leukosis. Acta Haemato1. $5: 321,1951$.

180. Takeuchi, T.: Histochemical demonstration of esterase in cells of peripheral blood and bone marrow smears. Medicine and Biol. 34:220, 1955.

181. Takeuchi, T.: Histochemical demonstration of branching enzyme in animal tissues. J. Histochem. Cytochem. 6:208, 1958 .

182. Takeuchi, T.: Histochemistry of enzymes in blood ce11s. Acta Haemato1. 21:371, 1958.

183. Takeuchi, T., Higashi, K., and Watanuki, S. : Distribution of amylophosphorylase in various tissues of human and mammalian organs. $J$. Histochem. Cytochem. 3:485, 1955. 
184. Takeuchi, T., and Kinoshita, K.: Histochemical demonstration of phosphorylase in blood and bone marrow cells. Blood 11:375, 1956.

185. Takeuchi, T., and Kuriaki, H.: Histochemical detection of phosphorylase in animal tissues. J. Histochem. Cytochem. 3:153, 1955.

186. Takeuchi, T., Tadokoro, N,, and Ide, H.: Histochemical study on glycogen synthesis from glucose-1phosphate in blood cells under normal and pathological conditions. J. Histochem. Cytochem. $10: 572,1962$ 。

187. Terent'eva, E. I., Krastoshevskaya, T. G., and Orlova, L. D.: A study of the electron microscopic structure of the hemopoietic tissue cells. II. Hemocytoblasts in acute leukemia. Problemy Gematol. Pere. Krovic.10:3, 1965.

188. Terner, J. Y., Schnur, J., and Gurland, J.: Stable Sudanophilia. Contributions to histochemistry of the Sudan dyes. Lab. Invest. 12:405, 1963. 
189. Traldi, A., Sternieri, E., Baldini, E., and Morini, A.: Glucidic metabolism and respiration of leukemic leukocytes. Soc. Ita1iana Biol. Speri. Bolletino $40: 1462,1964$.

190. Trubowitz, S., Feldman, D., Benante, C., and Hunt, V. M.: The alkaline phosphatase content of human polymorphonuclear leukocytes in blood and marrow. Am. J. Clin. Patho1。31:482, 1959.

191. Trubowitz, S. D., Feldman, D., Benante, C., and Kerman, D.: Metal requirements of alkaline phosphatases of human and rabbit leukocytes. Proc. Soc. Biol. Med. 95:35, 1957.

192. Tsou, K. C., Cheng, C. S., Nachlas, M. M., and Seligman, A. M.: Syntheses of some p-nitrophenyl substituted tetrazolium salts as electron acceptors for the demonstration of dehydrogenases. J. Am. Chem. Soc. $78: 6139,1956$.

193. Vaccari, F., Sabotto, B., and Manzini, E.: The alkaline phosphatase activity of leukocytes in shock. Blood 10:730, 1955 . 
194. Valentine, W. N.: The metabolism of the leukemic Ieukocyte. Am. J. Med. 28:699, 1960.

195. Valentine, W. N., and Beck, W. S.: Biochemical studies on leukocytes. I. Phosphatase activity in health, leucocytosis and myelocytic leucemia. J. Lab. C1in. Med。 $38: 39,1951$.

196. Valentine, W. N., Follette, J. H., and Lawrence, J. S.: The glycogen content of human leukocytes in health and in various disease states. J. C1in. Invest. $32: 251,1953$.

197. Valentine, W. N., Follette, J. H., Solomon, D. H., and Reynolds, J.: The relationship of leukocyte alkaline phosphatase to "stress", to ACTH and to adrena1 17-OH-corticosteroids. J. Lab. Clin. Med. $49: 723,1957$.

198. Vese11, E. S.: Lactate dehydrogenase isoenzymes: Substrate inhibition in various human tissues. Science $150: 1590,1965$.

199. Wachsmuth, E. D.: Effect of amitosis on the distribution of human lactic acid dehydrogenase isozymes. Nature 204:681, 1964 。 
200. Wachstein, M.: Alkaline phosphatase activity in normal and abnormal human blood and bone marrow cells. J. Lab. Clin. Med. 31:1, 1946. 201. Wachstein, M.: Distribution of histochemically demonstrable glycogen in human blood and bone marrow cells. Blood 4:54, 1949.

202. Wachstein, M.: Histochemistry of leukocytes. Leukocyte functions. Ann. N. Y. Acad. Sci. $59: 1052,1955$ 。

203. Wachstein, $M_{0}$, and Wolf, G.: The histochemical demonstration of esterase activity in human blood and bone marrow smears. J. Histochem. Cytochem. $6: 457,1958$.

204. Wa1ker, B. S., Lemon, H. M., Davison, M. M., and Schwartz, M. K.: Acid phosphatases. A review. Am. J. C1in。Path. 24:807, 1954.

205. West, E. S., and Todd, W. R.: Textbook of Biochemistry. New York, The Macmillan Co., 1961. 
206. West, M., Heller, P., and Zimmerman, H. J.: Serum enzymes in disease. III. Lactic dehydrogenase and glutamic oxaloacetic transaminase in patients with leukaemia and 1ymphoma. Am. J. Med. Sci. $235: 689,1958$.

207. Wetzel, B. H., Horn, R. G., and Spicer, S. S.: Cytochemical 1ocalization of non-specific phosphatase activity in rabbit myeloid elements. J. Histochem. Cytochem. 11:812, 1963.

208. Wiltshaw, E., and Maloney, W. C.: Histochemical and biochemical studies on leukocyte alkaline phosphatase activity. Blood 10:1120, 1955 .

209. Wintrobe, M. M.: Clinical Hematology. Philadelphia, Lea and Febiger, 1961.

210. Wislocki, G. B., and Dempsey, E. W.: Observation on the chemical cytology of normal blood and hemopoietic tissues. Anat. Record 96:249, 1946.

211. Wislocki, G. B., Rheingold, J. J., and Dempsey, E. W.: Occurreencoe of periodic acid-Schiff reaction in various normal cells of blood and connective tissues. Blood 4:562, 1949 . 
212. Wolman, M.: Study of the nature of 1ysosomes and of their acid phosphatase. Z. Zellforsch. $61: 1,1965$

213. Wulff, H. R.: Histochemical studies of leukocytes from an inflammatory exudate. Glycogen and phosphorylase. Acta Haemato1. 28:86, 1962 .

214. Wulff, W. R., and Sorensen, M.: A new technique for the histochemical demonstration of phosphorylase in blood films. Acta Haematol. $35: 304,1966$.

215. Wulff, W. R., and Wulff, H. R.: Histochemical demonstration of polysaccharides in blood cells using hexamine-silver technique. Danish Med. Bull. $11: 20,1964$.

216. Yamada, K.: The reactions of sulfated polysaccharides to several histochemical tests. J. Histochem. Cytochem. 12:327, 1964 .

217. Young, J. E., and Prager, M. D.: Some hydrolytic enzymes in normal and leukemic human leukocytes. J. Lab. C1in. Med. $60: 385,1962$. 